\title{
Gender differences in psychosocial status of adolescents during COVID-19: a six-country cross-sectional survey in Asia Pacific
}

Jun Wang ${ }^{1}$, Alec Aaron², Anurima Baidya², Christabel Chan ${ }^{3}$, Erica Wetzler ${ }^{4}$, Kevin Savage ${ }^{5}$, Michael Joseph ${ }^{4}$ and Yunhee Kang ${ }^{2^{*}}$

\begin{abstract}
Background: School closures and family economic instability caused by the COVID-19 lockdown measures have threatened the mental health and academic progress of adolescents. Through secondary data analysis of World Vision Asia Pacific Region's COVID-19 response-assessments in May-June 2020, this study examined whether adolescents' study, physical, and leisure activities, psychosocial status, and sources of COVID-19 information differed by gender.

Methods: The assessments used cross-sectional surveys of adolescents in poor communities served by World Vision ( $n=5552$ males and $n=6680$ females) aged 10-18 years old in six countries. The study households of adolescents were selected either by random sampling or non-probability convenience sampling and assessed using telephone or in-person interviews. Multivariate logistic regression analyses examined the relationship between gender and psychosocial status; daily activities (e.g., play, study); and sources of information about COVID-19.

Results: Participation in remote education was low (range: $0.5-20.7 \%$ across countries), with gender difference found only in Vietnam. Compared to males, female adolescents were less likely to play physically with a range of AOR: $0.36-$ 0.55 ( $n=5$ countries) or play video games with a range of AOR: $0.55-0.72$ ( $n=2$ countries). Female adolescents were more likely to feel isolated or stressed (India, $\mathrm{AOR}=1.13,95 \% \mathrm{Cl}: 1.00,1.26$ ); feel unsafe (the Philippines, $\mathrm{AOR}=2.22$, 95\%Cl:1.14, 4.33; Vietnam, AOR = 1.31, 95\%Cl:1.03, 1.47); be concerned about education (India, AOR = 1.24, 95\%Cl: 1.09, 1.41; Myanmar, AOR = 1.59, 95\%Cl:1.05, 2.40); or be concerned about household income (India, AOR = 1.13, 95\%Cl: 1.00, 1.28; Vietnam, $A O R=1.31,95 \% \mathrm{Cl}: 1.09,1.58)$. Female adolescents were also less likely to obtain COVID-19 related information through internet/social media (Bangladesh, $\mathrm{AOR}=0.51,95 \% \mathrm{Cl}: 0.41,0.64$; India, AOR $=0.84,95 \% \mathrm{Cl}: 0.73,0.96$; and Myanmar, $\mathrm{AOR}=0.65,95 \% \mathrm{Cl}: 0.43,0.97$ ) and mobile call or short message (India, AOR $=0.88,95 \% \mathrm{Cl}: 0.80,0.98)$ but more likely to get the information from friends (Vietnam, $A O R=1.18,95 \% \mathrm{Cl}: 1.02,1.36)$ and family (Bangladesh, $A O R=$ 1.44, 95\% Cl:1.21, 1.70; India, AOR =1.29, 95\% Cl:1.15, 1.45).
\end{abstract}

\footnotetext{
* Correspondence: ykang12@jhu.edu

2Johns Hopkins Bloomberg School of Public Health, Baltimore, MD, USA

Full list of author information is available at the end of the article
}

(c) The Author(s). 2021 Open Access This article is licensed under a Creative Commons Attribution 4.0 International License, which permits use, sharing, adaptation, distribution and reproduction in any medium or format, as long as you give appropriate credit to the original author(s) and the source, provide a link to the Creative Commons licence, and indicate if changes were made. The images or other third party material in this article are included in the article's Creative Commons. licence, unless indicated otherwise in a credit line to the material. If material is not included in the article's Creative Commons licence and your intended use is not permitted by statutory regulation or exceeds the permitted use, you will need to obtain permission directly from the copyright holder. To view a copy of this licence, visit http://creativecommons.org/licenses/by/4.0/ The Creative Commons Public Domain Dedication waiver (http://creativecommons.org/publicdomain/zero/1.0/) applies to the data made available in this article, unless otherwise stated in a credit line to the data. 
Conclusions: An understanding of gender differences in the impacts of COVID-19 on adolescents' schooling, physical, and mental health can inform adolescent protection interventions. Psychosocial support during response and recovery phases needs to pay special attention to gender differences, since female adolescents' psychosocial status is at higher risk when facing the challenges of this pandemic.

Keywords: Adolescents, Psychosocial status, COVID-19, Asia-Pacific region, Gender

\section{Background}

The COVID-19 pandemic has caused unprecedented changes to daily life, affecting the operation of everything, from economic markets to local education systems [1]. As of early September 2021, estimates project there have been over 200 million COVID-19 cases globally, with 4.5 million deaths [2]. The countries in the Asia Pacific region have been acutely impacted, representing a large proportion of the overall disease burden, with an estimated nearly 55 million cases and 850 thousand deaths [3].

Globally, the COVID-19 pandemic has negatively impacted the mental and physical health of caregivers, both familial and medical professionals. Healthcare workers, in particular, are exposed to novel job stressors that strongly deteriorate job satisfaction, life satisfaction, and heighten turnover rates $[4,5]$. A recent systematic review of Asia Pacific countries found that over onequarter of healthcare providers may have experienced depression, or anxiety, as a direct result of this pandemic [6]. Other studies from this region report these rates to be even greater, with increasing intensity among frontline workers [7-9]. The psychological and mental health consequences of COVID-19 are clear among healthcare professionals, but these tribulations are not unique to this employment category [10]. The general public has also witnessed a dramatic rise in the prevalence of mental illness [11-13].

In the United States, a survey from the Centers for Disease Control and Prevention found a 3 to 4 times increase in the rates of adverse mental or behavioral health conditions relative to 1 year prior among surveyed adults; and suicidal ideation was significantly higher among younger adults (18-24 years) group and unpaid adult-caregivers group [14]. Caregivers with children or adolescents who need special health care may also face increased stress [15].

As part of the restrictions on travel, business operations, social gatherings, or so-called "lockdowns" in response to the pandemic, most countries around the world have also temporarily shut down schools over the last year [16]. As schools closed their doors, education shifted from primarily being in-person to taking place within the home. Such a shift may change adolescents' learning behavior and have impacts on their self-efficacy and academic performance [17]. This has impacted more than 1.6 billion adolescents, or approximately $80 \%$ of the world's students [18].

Beyond education, the pandemic is having a substantial impact on adolescents' mental health. This is particularly concerning as adolescence is a period of heightened sensitivity to stress [19]. A meta-analysis showed a higher prevalence of anxiety, depression, and stress during COVID-19 pandemic than those reported before pandemic among college students [20]. Stressors arising from the pandemic, include, in addition to worries about education disruption, the restrictions on movement and social gathering, infection fears, financial loss, inadequate supplies or information, and stigma, can lead to a variety of negative psychological effects ranging from anxiety and depression to suicidal deaths [21]. One bright side of social isolation, allowing adolescents to spend more time with families, may serve as a source of mental balance if adolescents could receive adequate support from family members [22]. However, on the other hand, increased stressors faced by families (e.g., incoming loss, food insecurity, and parenting challenges) during the lockdown also may heighten children's risk of neglect, exploitation, abuse, and violence [23-25]. In general, young adolescents may not have enough coping skills to deal with the negative psychosocial consequences [26]. Without proper early intervention, the negative impacts will extend to their later life $[26,27]$.

In addition, school closure cut off an important channel to receive information and knowledge related to COVID-19 for school-aged adolescents in Asian Pacific countries. Evidence showed COVID-19 related knowledge, which has been proved to be significantly associated with risk perception and precautionary behaviors [28], is important for adolescents to protect them from being infected by the pandemic. However, even in the US, where published guidelines were easily to be obtained by individuals, a substantial proportion of college students were found not washing their hands as recommended by the CDC [29]. It is plausible that adolescents in Asian Pacific countries may have insufficient information to practice protective behaviors.

The disruption of education has also exacerbated gender-based inequality [30]. School closures are leading to even higher gender disparity in dropout rates as female students face barriers related to sexual and reproductive health and gendered socioeconomic factors [31]. 
Gender inequality in education has long been an issue in some Asian countries, where boys are prioritized for educational opportunities over girls [32, 33] and past evidence from India also suggests that school-aged females are likely to have higher dropout rates [34]. As families face difficulties girls may be forced to take on additional household responsibilities to cope with the economic stress of the family [35]. This is primarily influenced through cultural and religion context according to a cross-section study [36].

Beginning in adolescence, females show greater negative responses to stress than males, which may be associated with differences in physiological response systems [37]. Other evidence suggests that women are more likely to cope stress with emotional and avoidance styles and suffer more from physical and psychological distress symptoms than males [38].

This study aims to examine if adolescents' studying (i.e., studying at home, receiving remote education, and receiving online courses) and leisure activities (i.e., playing physically, watching TV, playing video games, and sleeping in daytime), psychosocial status, and sources of COVID-19 information differed by gender in Bangladesh, India, Indonesia, Myanmar, the Philippines, and Vietnam in the Asia Pacific Region. This paper describes the early experiences of adolescents with the COVID-19 pandemic. A better understanding of gender differences in the impacts of COVID-19 on adolescent's schooling, physical, and mental health can inform policies and guide the improvement of adolescent protection interventions.

\section{Methods}

\section{Data sources}

This study is a secondary analysis of data drawn from a set of surveys of adolescent children conducted by World Vision (WV) as part of a multi-country "Rapid Recovery Assessment”. The assessment was carried out in 402 of the communities in which WV works across 13 Asia Pacific countries: Bangladesh, Cambodia, India, Indonesia, Laos, Mongolia, Myanmar, Nepal, Philippines, Sri Lanka, Thailand, Timor-Leste and Vietnam in May 2020. The assessment focused on the socio-economic impact of COVID-19 on vulnerable households and their children in order to guide WV's continued programming to best support recovery from the effects of the pandemic.

The study uses data sets from the adolescent surveys in six of the 13 countries, which contains data of adolescents aged 10-18, who largely attended schools, from both urban and rural area, and excluding any respondents from 0 to 9 years of age. These surveyed a total of 12,232 adolescents ( $n=5552$ males; $n=6680$ females): 1599 from Bangladesh, 5595 from India, 812 from Indonesia, 386 from Myanmar, 421 from the Philippines, and 3419 from Vietnam (Table 1). The other countries were excluded for various reasons. The Nepal survey collected significantly different information than other countries. The sample sizes in Cambodia $(n=238)$, Laos $(n=72)$, and Mongolia $(n=47)$ were too small. The Thailand survey was only administered to rural households. However, the present study considered the location of residence as a major confounding variable. The surveys in Sri-Lanka and Timor-Leste did not include adolescents.

\section{COVID-19 preventive measures in Asia Pacific region}

In the Asia Pacific region, lockdown measures varied considerably between countries. In the first half of 2020, Bangladesh, the Philippines, and Vietnam had strict measures throughout the country; while in Indonesia and Myanmar, the measures were less strict and varied by locations [39-41]. In Myanmar, curfews were adopted by several regions, and a supplementary stay-at-home order was imposed by seven townships [40]. The Philippines experienced a long period of stay-at-home orders from mid-March to May and then again in August [42]. According to United Nations Educational, Scientific and Cultural Organization (UNESCO) [43], schools were closed country-wide until September 2020 in Bangladesh, India, Indonesia, Myanmar, and the Philippines. As a result, school-aged adolescents in the Asia-Pacific region faced substantial challenges and difficulties in daily life and to pursing education, though these differed between countries. One of the biggest issues, was availability and accessibility of temporary or emergency remote learning in lieu of physical school attendance. Governments in the Asia Pacific region responded with different strategies to mitigate the disadvantages brought by school closures. In Indonesia, India and Bangladesh, public broadcasters, using radio and television, were utilized to broadcast educational context to compensate the K-12 education [44, 45]. In Vietnam, adolescents returned to school from the beginning of May 2020, after more than 3 months' social distancing measures [46]. In Myanmar, school started to reopen from July, with free face masks and shields provided to teachers and students [47]; however, with the second wave of COVID-19 cases, students were sent home again at the end of August 2020 [48]. UNESCO [49] estimates that on average 22 weeks' school attendance has been lost so far across Eastern and South-Eastern Asia countries.

\section{Sampling methods}

In all countries, the sampling frame was the population of children living within the boundaries of the Area Programmes (APs) of the WV office, which is the basic organizational unit for WV's programming. It is a geographic area that consists of a community or set of 
Table 1 Demographic characteristics in Asia Pacific countries during early COVID-19

\begin{tabular}{|c|c|c|c|c|c|c|}
\hline & $\begin{array}{l}\text { Bangladesh } \\
(N=1599)\end{array}$ & $\begin{array}{l}\text { India } \\
(N=5595)\end{array}$ & $\begin{array}{l}\text { Indonesia } \\
(N=812)\end{array}$ & $\begin{array}{l}\text { Myanmar } \\
(N=386)\end{array}$ & $\begin{array}{l}\text { Philippines } \\
(N=421)\end{array}$ & $\begin{array}{l}\text { Vietnam } \\
(N=3419)\end{array}$ \\
\hline & n (\%) & n (\%) & n (\%) & n (\%) & n (\%) & n (\%) \\
\hline \multicolumn{7}{|l|}{ Type of Community } \\
\hline Rural & $1247(77.99)$ & $3871(69.19)$ & $733(90.27)$ & $80(20.73)$ & $311(73.87)$ & $3013(88.13)$ \\
\hline Urban & $352(22.01)$ & $1724(30.81)$ & 79 (9.73) & $306(79.27)$ & $110(26.13)$ & $406(11.87)$ \\
\hline \multicolumn{7}{|l|}{ Gender } \\
\hline Male & $701(43.84)$ & $2565(45.84)$ & $292(35.96)$ & $164(42.49)$ & $179(42.52)$ & $1651(48.29)$ \\
\hline Female & $898(56.16)$ & $3030(54.16)$ & $520(64.04)$ & $222(57.51)$ & $242(57.48)$ & $1768(51.71)$ \\
\hline \multicolumn{7}{|l|}{ Age } \\
\hline Younger Age (10-14 y) & $485(30.33)$ & $2993(53.49)$ & $476(58.62)$ & $230(59.59)$ & $216(51.31)$ & $1986(58.09)$ \\
\hline Older Age (15-18 y) & $1114(69.67)$ & $2602(46.51)$ & $336(41.38)$ & $156(40.41)$ & $205(48.69)$ & $1433(41.91)$ \\
\hline Age, Mean (SD) & $15.33(1.69)$ & $14.31(2.15)$ & $13.70(2.18)$ & $14.09(1.76)$ & $14.43(1.73)$ & $14.27(1.50)$ \\
\hline
\end{tabular}

Rural category included "Rural", "Other" and "Tribal" communities. Urban category included "Urban", "Semi-Urban" and "Slum" communities

communities within which WV collaborates for its longterm partnering to support sustainable development. All adolescent data came from a cross-sectional survey of households, within which a sub-set of adolescents were surveyed. Each country used different sampling approach and sample size determination, but largely, the sample size was aimed to have representative values for multiple variables at all sampled ADPs in each country. With some variation by country, available children in the selected households were all eligible to the child survey.

In Bangladesh, 50 households with children under 18 years old were selected randomly from each of 53 APs across 52 Upazilas of 24 districts from four regions. About 30 school going children (12-18 years of age) per AP were selected randomly for child survey. Thus total 1590 children were planned in this survey. If more than one child in a household, only the one enrolled in the Child Sponsorship Programming by World Vision would be interviewed.

In India, about 50 households from each of 111 APs and 30 household per seven special project areas were selected using non-probability convenience sampling. For the child survey, only households with children aged 10-18 years were included. Only one child per household was interviewed. If a household had more than one child, the interviewer interviewed a random child based on availability and comfort of that child.

In Indonesia, 247 out of 594 APs were selected, and a total of 20 adolescents were targeted in each AP in a way to get 10 respondents for households with 611 years of age and 10 respondents for households with 12-18 years of age. Only one child per household was interviewed. If a household has more than one child, interviewer asked for permission and willingness to the caregiver and the child about whom to be interviewed.
In Myanmar, a total of 31 APs from 46 districts in 13 of 14 States and Regions were randomly selected. Ten households were purposively sampled in each AP, with households hosting most vulnerable children (12-17 years old), children under 5 years old, pregnant and lactating women, children living with disabilities and Vision Fund Myanmar clients. If more than one child in households, the interview was made for older child; and if there were boys and girls in households, a boy was selected for the interview, according to the previous survey result that girls are mostly found than boys in a household.

In Vietnam, about 95 households (or 114 households based on AP who have 5 to 6 supervision areas) were randomly selected from 35 APs. If the interviewed household does not have any child aged $12-18$ years or the child is absent from the survey location during the assessment, the enumerator selected a child from the nearest household in the COVID-19 Response participant list. If one household have more than one child aged $12-18$ years, the interviewers interviewed both two children as they may have different opinions even they live in the same household.

In the Philippines, a total of 28 APs in Luzon, Visayas and Mindanao covering 229 barangays (the smallest administrative division in the Philippines) were selected. Only one child per household was interviewed. If more than one child in a household, the interview was made for a random child aged 12-17 years old based on availability and comfort.

\section{Data collection}

The surveys used structured questionnaires that collected information from adolescents about their demographic characteristics (gender, age, residence); study and leisure activities; psychosocial status (feelings of 
happiness, unhappiness, isolation, stress, and concerns; and reasons for these); parental discipline; sources of COVID-19 information; perceptions of COVID-19; and their plans for after the lockdown.

Questionnaires were created in standard electronic document format (Microsoft Word or Excel) and translated into local languages. There was a master questionnaire, but additionally contextualized questions were included in each country. These were then transformed into electronic data-collection format using Kobo Toolbox. Data were then collected by interview and entered directly into Android tablets mostly through telephone conversation, or in-person when feasible, with appropriate COVID-19 protocols regarding social distancing and using personal protective equipment.

In each country, World Vision AP staff or non-AP staff were engaged in conducting phone surveys. The data collectors underwent training and pilot tests prior to collecting the information to become acquainted with the survey tools, using smartphones for data collection, and to understand the key objectives and aims of the assessment.

The interviewers provided the details of purpose and contents of the survey to the parents of the adolescent through mobile phones or household visits in remote areas where the covid-19 cases are few, and received verbal consent from the parents or legal guardians of adolescents (under 18 years old) and assent from adolescents themselves. All subjects completed the surveys voluntarily and the information collected via the survey was anonymized to maintain confidentiality. All methods were carried out in accordance with relevant guidelines and regulations.

\section{Available variables}

Independent variables The independent variable is adolescent gender (male vs. female).

Dependent variables Questions assessing the impact of the lockdown on the adolescent mental health included whether the adolescent was feeling isolated or stressed and understanding any specific concerns the adolescent might have due to the stay-at-home orders. This included 1) study and playing activity during restriction; 2 ) negative psychosocial status; and 3) information sources of COVID-19.

The study and playing activity during restriction included 1) studying (i.e., all types of study activities), 2) remote education by school, 3) online courses, 4) playingphysically, 5) sleeping during daytime, 6) watching TV, and 7) playing games on TV, phones, and tablets. Since most schools were closed across these six countries when the data were collected in May 2020, variables describing the main daily activities of adolescents were collected. Adolescents were asked about how many hours they spent on each activity throughout the day.

Assessment of psychosocial status for being required to stay at home during COVID-19 included the following areas: 1) feeling isolated/stressed, 2) worrying about getting sick, 3) concerns about not going to school, 4) concerns about missing friends, 5) concerns about household income or food security, and 6) feeling unsafe or insecure.

The types of information source about COVID-19 included 1) internet/social media, 2) mobile phone (phone call/text), 3) friends, 4) family, and 5) TV.

Confounding variables The confounding variables included in the regression models are type of residence (rural or urban), and young age (10-14 y) versus older age (15-18 y).

\section{Statistical analysis}

Exploratory data analysis was conducted to present proportions for categorical variables and mean (standard deviation) for continuous variables. Chi- squared analysis was used to test difference for categorical variables and Student t-test for continuous variables. Odds ratios (OR), 95\% confidence intervals $(\mathrm{CI})$, and $p$-values were calculated through univariate and multivariable logistic regression of 1) the studying and leisure activity during restriction; 2) psychosocial status; and 3) information source on COVID-19 by adolescent gender. $P$-values less than 0.05 or $95 \%$ CI of odds ratios (ORs) not including 1.00 were considered to be statistically significant. Multivariable logistic regression was adjusted for type of residence (rural vs. urban) and adolescent age, and clustering at project area unit in each country. Stata 16.0 (Stata Corporation, College Station, TX, USA) was used for data management and statistical analysis.

\section{Results}

\section{Demographic characteristics}

The majority of adolescents in this study lived in rural area (69.2-90.3\%) (Table 1). The number of female participants were slightly more than the males across these six countries from $51.7 \%$ in Vietnam to $64.0 \%$ in Indonesia. Bangladesh population had a larger proportion $(69.7 \%)$ of individuals in the older age group (1518 years old) than in the younger group (10-14 years old), while other countries had a greater proportion of younger adolescents (51.3-59.6\%).

\section{Daily activity during restriction caused by COVID-19 Study activities}

Although the proportion of adolescents who studied in the past day varied by country (16.6-86.1\%), the 
percentages of adolescents who received remote education $(0.5-20.7 \%)$ or online courses $(0.5-14.4 \%)$ were low across all six countries (Table 2 \& Fig. 1). Adjusting for the type of community and age, in Vietnam, female adolescents had 1.73 times higher odds of spending time on study at home (AOR $=1.73,95 \% \mathrm{CI}: 1.39,2.16, p<0.001)$, 1.23 times higher odds of having remote education $(\mathrm{AOR}=1.23,95 \% \mathrm{CI}: 1.03,1.48, p=0.02)$, and 1.74 times $(\mathrm{AOR}=1.74,95 \% \mathrm{CI}: 1.28,2.37, \mathrm{p}<0.001)$ higher odds of having online courses during a day, compared to male adolescents. Female adolescents in Bangladesh and India also tended to spend more time on studying at home than their male peers, although the differences were not statistically significant ( $p=0.08 \& p=0.05$, respectively).

\section{Leisure activities}

The proportion of physical activity was moderate from 42.1 to $85.2 \%$. Female adolescents played less physically (35.8-81.4\%) than the male adolescents (46.6-89.8\%) in six countries and significantly lower in the five out of these six countries (Bangladesh, AOR $=0.55,95 \% \mathrm{CI}$ : $0.42,0.73, p<0.001$; India, $\mathrm{AOR}=0.49,95 \% \mathrm{CI}: 0.39$, $0.62, \mathrm{p}<0.001$; Myanmar, AOR $=0.36,95 \% \mathrm{CI}: 0.23,0.58$, $\mathrm{p}<0.001$; the Philippines, AOR $=0.49,95 \% \mathrm{CI}: 0.30,0.82$, $p=0.006$; and Vietnam, AOR $=0.49,95 \% \mathrm{CI}: 0.41,0.60$, $\mathrm{p}<0.001$, respectively) (Table $2 \&$ Fig. 2). Female adolescents had 1.26 times (95\%CI:1.10, 1.43, $p=0.001$ ), 1.95 times (95\%CI:1.27, 3.00, $p=0.002$ ), and 1.22 times (95\%CI:1.05, 1.42, $p=0.01$ ) higher odds of sleeping in daytime than their male counterparts in India, Myanmar, and Vietnam, respectively. The proportion of watching $\mathrm{TV}$ in the previous day was as high as 36.7 to $77.0 \%$ in the six countries. No significant associations were found between gender and watching TV across six countries. Playing video game was more common in male (24.0 to $70.2 \%$ ) than female adolescents (16.4 to 63.3\%) in six countries. Significantly lower odds were found among females in Bangladesh (AOR $=0.65,95 \% \mathrm{CI}: 0.50,0.84, p=$ 0.001 ), India ( $\mathrm{AOR}=0.72$, 95\%CI:0.63, 0.82, $p<0.001$ ), Indonesia ( $\mathrm{AOR}=0.61,95 \% \mathrm{CI}: 0.42,0.90, p=0.01)$, and Vietnam $(\mathrm{AOR}=0.55,95 \% \mathrm{CI}: 0.47,0.65, \mathrm{p}<0.001)$ than males.

\section{Psychosocial status \\ Feeling isolated/stressed}

Bangladesh had the largest percentage of both male adolescents (87.3\%) and female adolescents (86.86\%) who felt isolated or stressed than the remaining countries (Table 3 \& Fig. 3). In India, female adolescents had 1.13 times (95\%CI:1.00, 1.26, $p=0.047$ ) higher odds of feeling isolated or stressed than male adolescents (Fig. 4). Although not statistically significant, female adolescents in Vietnam showed marginally a higher risk at feeling isolated than male adolescents $(\mathrm{AOR}=1.18,95 \% \mathrm{CI}: 0.99$, $1.40, p=0.06)$.

\section{Worrying about getting sick}

The proportion of respondents worrying about getting sick ranged from $14.5 \%$ in Myanmar to $42.9 \%$ in Vietnam. Across the six countries, there was no significant difference between female and male adolescents in worrying about getting sick (Table 3, Figs. 3 \& 4).

\section{Concerns for not going to school}

In Bangladesh, India, the Philippines, and Vietnam, more than $50 \%$ of adolescents (both males and females) reported concerns for not going to school. Female adolescents in India and Myanmar had 1.24 times (95\%CI:1.09, 1.41, $p=0.001$ ) and 1.59 times (95\%CI:1.05, 2.40, $p=$ 0.03) higher odds of concerning for not going to school compared to male adolescents (Table 3, Figs. 3 \& 4).

\section{Concerns for missing friends}

In India and Bangladesh, 68.3 and 81.3\% of respondents, respectively, presented concerns for missing friends, which was relatively higher than the other countries. No significant relationships between gender and concerns for missing friends were found across these six countries (Table 3, Figs. 3 \& 4).

\section{Concerns for household income or food security}

About 60\% Bangladesh adolescents expressed the concern of household income or food security, which was higher than other five countries. Female adolescents had higher odds compared to male adolescents in India $(\mathrm{AOR}=1.13 ; 95 \% \mathrm{CI}: 1.00,1.28, p=0.049)$ and Vietnam $(\mathrm{AOR}=1.31 ; 95 \% \mathrm{CI}: 1.09,1.58, p=0.005)$, while other countries did not show significant gender difference (Table 3, Figs. 3 \& 4).

\section{Feeling unsafe or insecure}

The findings of feeling unsafe or insecure is mixed among countries. Female adolescents in the Philippines and Vietnam had 2.22 times (95\%CI:1.14, 4.33, $p=0.02$ ) and 1.23 times $(95 \% \mathrm{CI}: 1.03,1.47, \mathrm{p}=0.02)$ higher odds about feeling unsafe or insecure than their male counterparts. However, female adolescents had lower odds (AOR $=0.44 ; 95 \% \mathrm{CI}: 0.20,0.98, p=0.04)$ of feeling unsafe, compared to male adolescents in Myanmar (Table 3, Figs. 3 \& 4).

\section{Information access related to the COVID-19 Television}

Generally, television was the most common source of COVID-19 information among respondents (74.188.1\%) in all countries (Table 4). There was no 
Table 2 Logistic regressions of adolescent gender for daily activities in Asia Pacific countries during early COVID-19

\begin{tabular}{|c|c|c|c|c|c|c|c|c|c|}
\hline & Total & Male & Female & Male & Female & $p$ value & Male & Female & $p$ value \\
\hline Studying at home & N (\%) & n (\%) & n (\%) & COR & COR $(95 \% \mathrm{Cl})$ & & $A O R$ & AOR $(95 \% \mathrm{Cl})$ & \\
\hline Bangladesh $(n=1599)$ & $1206(75.42)$ & $512(73.04)$ & $694(77.28)$ & 1.00 & $1.26(1.00,1.57)$ & 0.046 & 1.00 & $1.22(0.98,1.54)$ & 0.08 \\
\hline India $(n=5595)$ & 4815 (86.06) & $2175(84.80)$ & $2640(87.13)$ & 1.00 & $1.21(0.99,1.49)$ & 0.06 & 1.00 & $1.22(0.998,1.49)$ & 0.05 \\
\hline Indonesia $(n=812)$ & $496(61.08)$ & $178(60.96)$ & $318(61.15)$ & 1.00 & $1.01(0.75,1.35)$ & 0.96 & 1.00 & $1.00(0.75,1.35)$ & 0.98 \\
\hline Myanmar $(n=386)$ & 64 (16.58) & $25(15.24)$ & $39(17.57)$ & 1.00 & $1.18(0.67,2.10)$ & 0.56 & 1.00 & $1.19(0.68,2.09)$ & 0.54 \\
\hline Philippines $(n=421)$ & $144(34.20)$ & 55 (30.73) & 89 (36.78) & 1.00 & $1.31(0.82,2.10)$ & 0.26 & 1.00 & $1.37(0.85,2.21)$ & 0.19 \\
\hline Vietnam $(n=3419)$ & $2655(77.65)$ & $1201(72.74)$ & $1454(82.24)$ & 1.00 & $1.74(1.38,2.18)$ & $<0.001$ & 1.00 & $1.73(1.39,2.16)$ & $<0.001$ \\
\hline \multicolumn{10}{|c|}{ Remote education by school } \\
\hline Bangladesh $(n=1599)$ & $226(14.13)$ & $87(12.41)$ & $139(15.48)$ & 1.00 & $1.29(0.87,1.93)$ & 0.21 & 1.00 & $1.24(0.82,1.86)$ & 0.31 \\
\hline India $(n=5595)$ & $1160(20.73)$ & $540(21.05)$ & $620(20.46)$ & 1.00 & $0.96(0.84,1.11)$ & 0.61 & 1.00 & $0.96(0.84,1.11)$ & 0.60 \\
\hline Indonesia $(n=812)$ & $87(10.71)$ & $37(12.67)$ & $50(9.62)$ & 1.00 & $0.73(0.46,1.18)$ & 0.20 & 1.00 & $0.76(0.48,1.21)$ & 0.25 \\
\hline Myanmar $(n=386)$ & $2(0.52)$ & $1(0.61)$ & $1(0.45)$ & 1.00 & $0.74(0.05,11.99)$ & 0.83 & 1.00 & $0.76(0.04,13.29)$ & 0.85 \\
\hline Philippines ( $n=421$ ) & $32(7.60)$ & $8(4.47)$ & $24(9.92)$ & 1.00 & $2.35(1.02,5.41)$ & 0.044 & 1.00 & $2.30(0.96,5.50)$ & 0.06 \\
\hline Vietnam $(n=3419)$ & $214(6.26)$ & $93(5.63)$ & $121(6.84)$ & 1.00 & $1.23(1.03,1.47)$ & 0.023 & 1.00 & $1.23(1.03,1.48)$ & 0.024 \\
\hline \multicolumn{10}{|l|}{ Online courses } \\
\hline Bangladesh $(n=1599)$ & $76(4.75)$ & $31(3.45)$ & $45(6.42)$ & 1.00 & $1.14(0.70,1.87)$ & 0.60 & 1.00 & $1.24(0.75,2.05)$ & 0.41 \\
\hline India $(n=5595)$ & 805 (14.39) & $362(14.11)$ & $443(14.62)$ & 1.00 & $1.04(0.90,1.21)$ & 0.58 & 1.00 & $1.03(0.89,1.20)$ & 0.70 \\
\hline Indonesia $(n=812)$ & $5(0.62)$ & $2(0.68)$ & $3(0.58)$ & 1.00 & $0.84(0.13,5.25)$ & 0.85 & 1.00 & $0.83(0.13,5.43)$ & 0.85 \\
\hline Myanmar $(n=386)$ & $2(0.52)$ & $2(1.22)$ & $0(0.00)$ & 1.00 & - & - & 1.00 & - & - \\
\hline Philippines ( $n=421$ ) & $18(4.28)$ & $7(3.91)$ & $11(4.55)$ & 1.00 & $1.17(0.37,3.74)$ & 0.79 & 1.00 & $1.11(0.35,3.56)$ & 0.86 \\
\hline Vietnam $(n=3419)$ & $187(5.47)$ & $67(4.06)$ & $120(6.79)$ & 1.00 & $1.72(1.27,2.33)$ & $<0.001$ & 1.00 & $1.74(1.28,2.37)$ & $<0.001$ \\
\hline \multicolumn{10}{|l|}{ Playing-physically } \\
\hline Bangladesh $(n=1599)$ & $673(42.05)$ & $352(50.21)$ & $321(35.75)$ & 1.00 & $0.55(0.42,0.72)$ & $<0.001$ & 1.00 & $0.55(0.42,0.73)$ & $<0.001$ \\
\hline India $(n=5595)$ & $4768(85.22)$ & 2303 (89.79) & 2465 (81.35) & 1.00 & $0.50(0.40,0.62)$ & $<0.001$ & 1.00 & $0.49(0.39,0.62)$ & $<0.001$ \\
\hline Indonesia $(n=812)$ & 355 (43.72) & $136(46.58)$ & 219 (42.12) & 1.00 & $0.83(0.62,1.12)$ & 0.23 & 1.00 & $0.83(0.61,1.13)$ & 0.23 \\
\hline Myanmar $(n=386)$ & $208(53.89)$ & $110(67.07)$ & $98(44.14)$ & 1.00 & $0.39(0.25,0.61)$ & $<0.001$ & 1.00 & $0.36(0.23,0.58)$ & $<0.001$ \\
\hline Philippines $(n=421)$ & 205 (48.69) & $105(58.66)$ & $100(41.32)$ & 1.00 & $0.50(0.30,0.82)$ & 0.007 & 1.00 & $0.49(0.30,0.82)$ & 0.006 \\
\hline Vietnam $(n=3419)$ & $1736(50.78)$ & $984(59.60)$ & $752(42.53)$ & 1.00 & $0.50(0.41,0.61)$ & $<0.001$ & 1.00 & $0.49(0.41,0.60)$ & $<0.001$ \\
\hline \multicolumn{10}{|l|}{ Sleeping in daytime } \\
\hline Bangladesh $(n=1599)$ & $1102(68.92)$ & $474(67.62)$ & $628(69.93)$ & 1.00 & $1.11(0.92,1.35)$ & 0.27 & 1.00 & $1.13(0.93,1.37)$ & 0.23 \\
\hline India $(n=5595)$ & $4311(77.05)$ & $1921(74.89)$ & $2390(78.88)$ & 1.00 & $1.25(1.09,1.43)$ & 0.001 & 1.00 & $1.26(1.10,1.43)$ & 0.001 \\
\hline Indonesia $(n=812)$ & $214(26.35)$ & $81(27.74)$ & $133(25.58)$ & 1.00 & $0.90(0.65,1.24)$ & 0.51 & 1.00 & $0.90(0.65,1.26)$ & 0.55 \\
\hline Myanmar $(n=386)$ & $194(50.26)$ & $67(40.85)$ & $127(57.21)$ & 1.00 & $1.94(1.25,3.01)$ & 0.003 & 1.00 & $1.95(1.27,3.00)$ & 0.002 \\
\hline Philippines ( $n=421$ ) & $297(70.54)$ & $120(67.04)$ & $177(73.14)$ & 1.00 & $1.34(0.90,1.99)$ & 0.15 & 1.00 & $1.33(0.88,2.02)$ & 0.18 \\
\hline Vietnam $(n=3419)$ & $805(23.54)$ & $358(21.68)$ & $447(25.28)$ & 1.00 & $1.22(1.05,1.42)$ & 0.010 & 1.00 & $1.22(1.05,1.42)$ & 0.010 \\
\hline \multicolumn{10}{|l|}{ Watching TV } \\
\hline Bangladesh $(n=1599)$ & $1124(70.29)$ & $484(69.04)$ & $640(71.27)$ & 1.00 & $1.11(0.89,1.40)$ & 0.35 & 1.00 & $1.08(0.86,1.36)$ & 0.52 \\
\hline India $(n=5595)$ & $4308(77.00)$ & $1981(77.23)$ & $2327(76.80)$ & 1.00 & $0.98(0.86,1.11)$ & 0.71 & 1.00 & $0.98(0.85,1.11)$ & 0.72 \\
\hline Indonesia $(n=812)$ & $298(36.7)$ & $106(36.30)$ & $192(36.92)$ & 1.00 & $1.03(0.78,1.35)$ & 0.84 & 1.00 & $1.03(0.78,1.36)$ & 0.82 \\
\hline Myanmar $(n=386)$ & 229 (59.33) & $90(54.88)$ & $139(62.61)$ & 1.00 & $1.38(0.82,2.31)$ & 0.23 & 1.00 & $1.38(0.82,2.32)$ & 0.23 \\
\hline Philippines $(n=421)$ & $322(76.48)$ & $144(80.45)$ & $188(77.69)$ & 1.00 & $0.85(0.58,1.24)$ & 0.39 & 1.00 & $0.83(0.55,1.25)$ & 0.37 \\
\hline Vietnam $(n=3419)$ & $1956(57.21)$ & $927(56.15)$ & $1029(58.20)$ & 1.00 & $1.09(0.93,1.27)$ & 0.29 & 1.00 & $1.09(0.93,1.28)$ & 0.27 \\
\hline
\end{tabular}

Playing games in TV, Phones, tabs, etc. (using electronic devices) 
Table 2 Logistic regressions of adolescent gender for daily activities in Asia Pacific countries during early COVID-19 (Continued)

\begin{tabular}{|c|c|c|c|c|c|c|c|c|c|}
\hline & Total & Male & Female & Male & Female & $p$ value & Male & Female & $p$ value \\
\hline Bangladesh $(n=1599)$ & 625 (39.09) & $318(45.36)$ & 307 (34.19) & 1.00 & $0.63(0.48,0.82)$ & 0.001 & 1.00 & $0.65(0.50,0.84)$ & 0.001 \\
\hline India $(n=5595)$ & $3718(66.45)$ & $1801(70.21)$ & $1917(63.27)$ & 1.00 & $0.73(0.65,0.83)$ & $<0.001$ & 1.00 & $0.72(0.63,0.82)$ & $<0.001$ \\
\hline Indonesia $(n=812)$ & 155 (19.09) & 70 (23.97) & 85 (16.35) & 1.00 & $0.62(0.43,0.89)$ & 0.011 & 1.00 & $0.61(0.42,0.90)$ & 0.013 \\
\hline Myanmar $(n=386)$ & $127(32.90)$ & $61(37.20)$ & 66 (29.73) & 1.00 & $0.71(0.46,1.10)$ & 0.13 & 1.00 & $0.72(0.47,1.10)$ & 0.13 \\
\hline Philippines $(n=421)$ & $240(57.00)$ & $104(58.10)$ & $136(56.20)$ & 1.00 & $0.93(0.63,1.36)$ & 0.69 & 1.00 & $0.94(0.64,1.36)$ & 0.73 \\
\hline Vietnam $(n=3419)$ & $833(24.36)$ & 495 (29.98) & 338 (19.12) & 1.00 & $0.55(0.47,0.64)$ & $<0.001$ & 1.00 & $0.55(0.47,0.65)$ & $<0.001$ \\
\hline
\end{tabular}

AOR models were adjusted by type of community (rural vs urban) and adolescents age (years)

significant difference in watching TV by adolescent gender across the six countries.

\section{Internet/social media}

Relatively smaller percentages of adolescents in Indonesia and Myanmar got such information through the internet (35.96 and $27.7 \%$, respectively) compared to other countries (41.9-67.5\%). Female adolescents were less likely to get information from the internet or social media than male adolescents in Bangladesh (AOR $=0.51,95 \% \mathrm{CI}: 0.41$, 0.64, $p<0.001$ ), India (AOR $=0.84,95 \% \mathrm{CI}: 0.73,0.96, p=$ 0.01 ), and Myanmar (AOR $=0.65,95 \% \mathrm{CI}: 0.43,0.97, \mathrm{p}=$ 0.04). But in the Philippines, female adolescents had 1.85 times (95\%CI:1.27, 2.70, $p=0.001$ ) higher odds of receiving COVID-19 information from the internet than male counterparts.

\section{Phone call / SMS}

The percentages of using phone call or short massage to receive COVID-19 information were only 16.3, 13.0 and $16.6 \%$ in Indonesia, Myanmar, and the Philippines respectively. In India, female adolescents had lower odds $(\mathrm{AOR}=0.88 ; 95 \% \mathrm{CI}: 0.80,0.98, p=0.01)$ of receiving COVID-19 information through mobile sources than male adolescents. No significant difference by gender in receiving information via phone call or massages were found in other five countries.

\section{Friends}

Friends (10.0-53.5\%) was a major channel to get COVID-19 related information. For utilizing friends as information sources, female participants had 1.18 times (95\%CI:1.02, 1.36, $p=0.03$ ) higher odds than males in

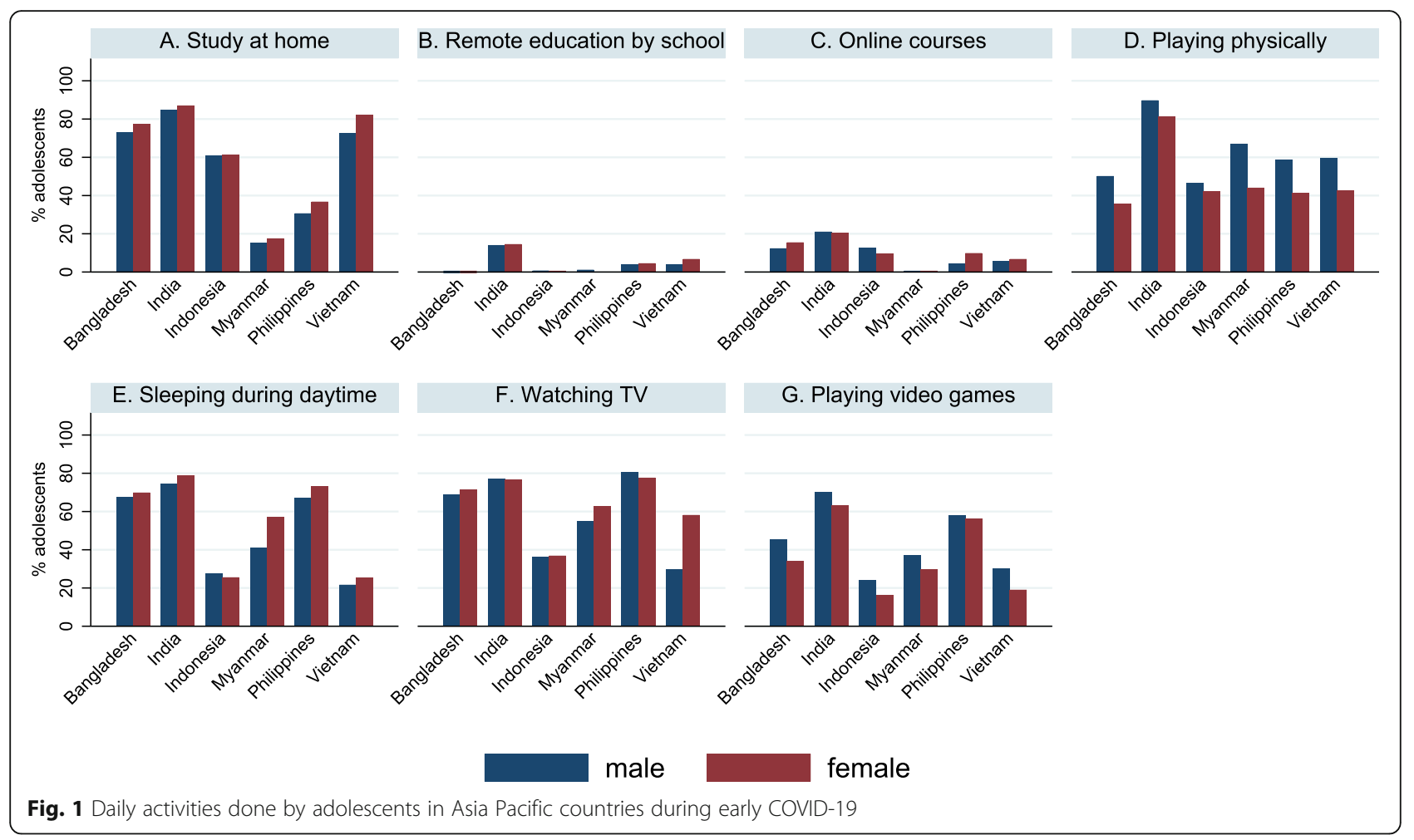




\section{A. Study at home}

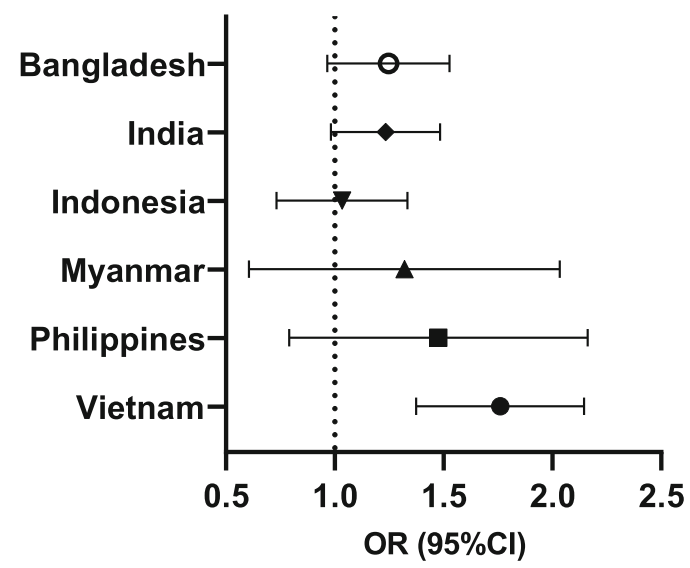

\section{Wathing TV}

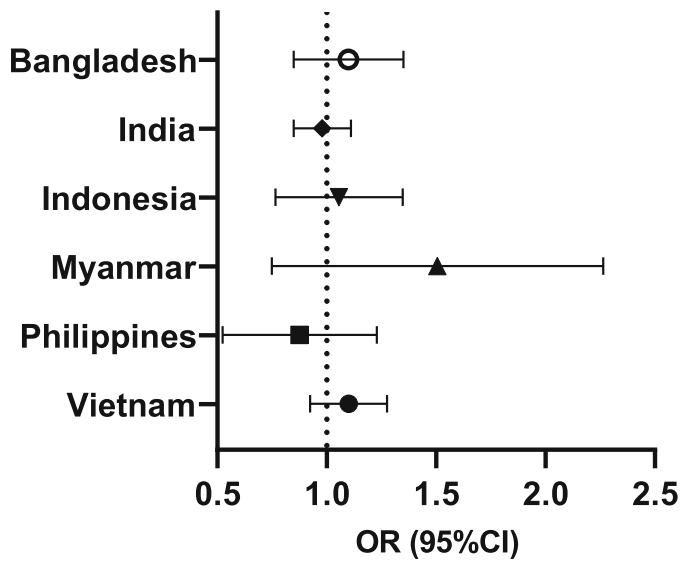

B. Playing physically

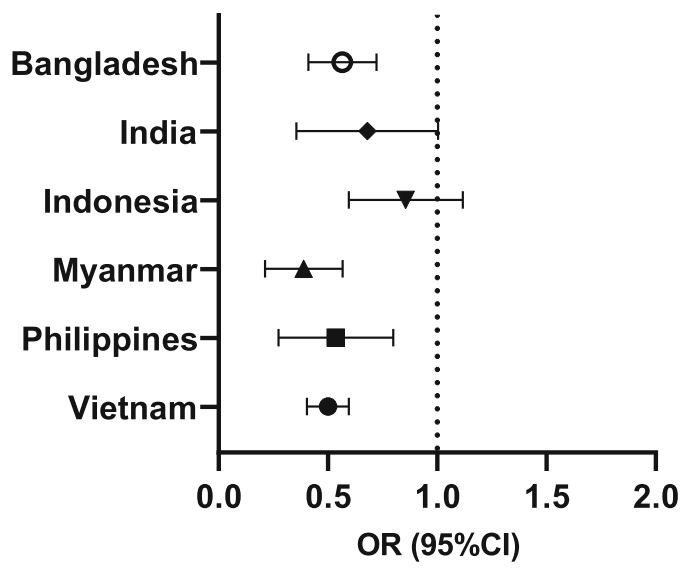

D. Playing TV/online games

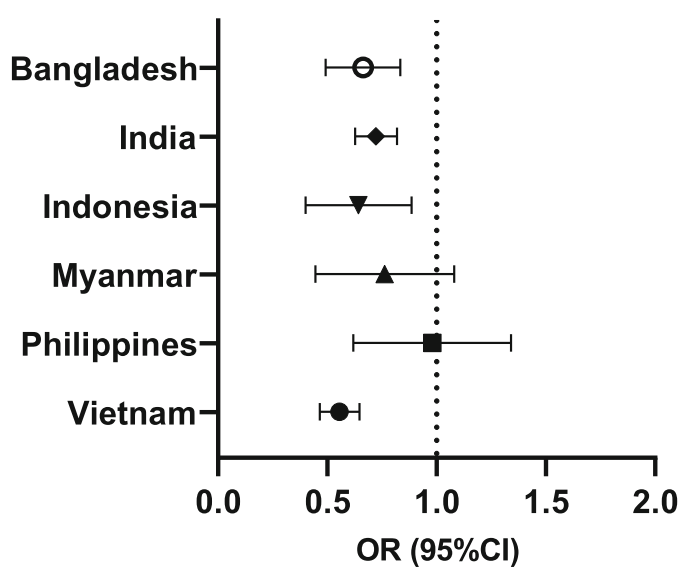

Fig. 2 Associations between adolescent gender and daily activities in Asia Pacific countries during early COVID-19

Vietnam. The patterns were mixed and not significant among other five countries.

\section{Family}

Family was mentioned with a range of $27.3-61.5 \%$ in six countries Female adolescents were 1.44 times (95\%CI: $1.21,1.70, p<0.001)$ and 1.29 times (95\%CI:1.15, 1.45, $\mathrm{p}<0.001)$ more likely to receive information from their family, compared to male adolescents in Bangladesh and India.

\section{Discussion}

To our knowledge, this study was the first multi-country study to investigate the differences in psychosocial status among male and female adolescents impacted by the COVID-19 pandemic in the Asia Pacific region. This study provides evidence for response and recovery strategies from COVID-19 by analyzing adolescents' daily activities, stressors, and information acquisition channels. Findings suggested that COVID-19 lockdown measures had different impacts on adolescent mental health or psychosocial status by gender in these six countries, but with some variations. In Bangladesh and Indonesia, higher percentages of adolescents felt stressed and isolated by COVID-19 than in other countries. Female adolescents were more likely to have concerns related to the COVID-19 pandemic than males. Gender differences were also found in daily activities. Male adolescents were more likely to report engaging in physical activities and video games than females in general. In terms of study activities, online or remote education was accessed by only limited percentages of adolescents. With regard to 
Table 3 Logistic regressions of adolescent gender for current concerns in Asia Pacific countries during early COVID-19

\begin{tabular}{|c|c|c|c|c|c|c|c|c|c|}
\hline & Total & Male & Female & Male & Female & $p$ value & Male & Female & $p$ value \\
\hline Feeling stressed or isolated & n (\%) & n (\%) & n (\%) & COR & COR $(95 \% \mathrm{Cl})$ & & $\mathrm{AOR}$ & AOR $(95 \% \mathrm{Cl})$ & \\
\hline Bangladesh $(n=1599)$ & $1392(87.05)$ & $619(87.30)$ & $780(86.86)$ & 1.00 & $0.96(0.66,1.39)$ & 0.83 & 1.00 & $0.98(0.69,1.40)$ & 0.93 \\
\hline India $(n=5595)$ & $2227(39.80)$ & $981(38.25)$ & $1246(41.12)$ & 1.00 & $1.13(1.00,1.27)$ & 0.05 & 1.00 & $1.13(1.00,1.26)$ & 0.047 \\
\hline Indonesia $(n=812)$ & $472(58.13)$ & $173(59.25)$ & $299(57.50)$ & 1.00 & $0.93(0.73,1.19)$ & 0.57 & 1.00 & $0.93(0.72,1.20)$ & 0.56 \\
\hline Myanmar $(n=386)$ & $111(28.76)$ & $52(31.71)$ & $59(26.58)$ & 1.00 & $0.78(0.50,1.22)$ & 0.28 & 1.00 & $0.77(0.49,1.21)$ & 0.26 \\
\hline Philippines $(n=421)$ & $187(44.42)$ & $76(42.46)$ & $111(45.87)$ & 1.00 & $1.15(0.74,1.79)$ & 0.54 & 1.00 & $1.13(0.72,1.78)$ & 0.59 \\
\hline Vietnam $(n=3419)$ & $1002(29.31)$ & $453(27.44)$ & $549(31.05)$ & 1.00 & $1.19(1.01,1.41)$ & 0.038 & 1.00 & $1.18(0.99,1.40)$ & 0.06 \\
\hline \multicolumn{10}{|l|}{ Worry about getting sick } \\
\hline Bangladesh $(n=1599)$ & $626(39.15)$ & $270(38.52)$ & $356(39.64)$ & 1.00 & $1.05(0.86,1.29)$ & 0.65 & 1.00 & $1.05(0.86,1.30)$ & 0.62 \\
\hline India $(n=5595)$ & $1505(26.90)$ & $656(25.58)$ & $849(28.02)$ & 1.00 & $1.13(0.96,1.33)$ & 0.13 & 1.00 & $1.13(0.97,1.32)$ & 0.13 \\
\hline Indonesia $(n=812)$ & $280(34.48)$ & $110(37.67)$ & 170 (32.69) & 1.00 & $0.80(0.61,1.05)$ & 0.11 & 1.00 & $0.82(0.63,1.07)$ & 0.15 \\
\hline Myanmar $(n=386)$ & $56(14.51)$ & $25(15.24)$ & 31 (13.96) & 1.00 & $0.90(0.44,1.86)$ & 0.78 & 1.00 & $0.89(0.43,1.84)$ & 0.75 \\
\hline Philippines $(n=421)$ & $145(34.44)$ & $60(33.52)$ & 85 (35.12) & 1.00 & $1.07(0.75,1.53)$ & 0.70 & 1.00 & $1.07(0.78,1.49)$ & 0.67 \\
\hline Vietnam $(n=3419)$ & $1467(42.94)$ & 691 (41.93) & 776 (43.89) & 1.00 & $1.08(0.94,1.25)$ & 0.26 & 1.00 & $1.08(0.94,1.24)$ & 0.28 \\
\hline \multicolumn{10}{|c|}{ Concerns for not going to school } \\
\hline Bangladesh $(n=1599)$ & $1244(77.80)$ & $530(75.61)$ & $714(79.51)$ & 1.00 & $1.25(0.97,1.62)$ & 0.09 & 1.00 & $1.23(0.95,1.60)$ & 0.12 \\
\hline India $(n=5595)$ & $3843(68.69)$ & $1699(66.24)$ & $2144(70.76)$ & 1.00 & $1.23(1.08,1.40)$ & 0.002 & 1.00 & $1.24(1.09,1.41)$ & 0.001 \\
\hline Indonesia $(n=812)$ & $277(34.11)$ & $98(33.56)$ & $179(34.42)$ & 1.00 & $1.04(0.80,1.34)$ & 0.77 & 1.00 & $1.02(0.78,1.34)$ & 0.86 \\
\hline Myanmar $(n=386)$ & $107(27.72)$ & $37(22.56)$ & $70(31.53)$ & 1.00 & $1.58(1.04,2.40)$ & 0.032 & 1.00 & $1.59(1.05,2.40)$ & 0.028 \\
\hline Philippines $(n=421)$ & $248(58.91)$ & $105(58.66)$ & $143(59.09)$ & 1.00 & $1.02(0.66,1.57)$ & 0.94 & 1.00 & $1.02(0.66,1.58)$ & 0.94 \\
\hline Vietnam $(n=3419)$ & $2048(59.95)$ & $961(58.31)$ & $1087(61.48)$ & 1.00 & $1.14(0.98,1.33)$ & 0.09 & 1.00 & $1.14(0.98,1.32)$ & 0.09 \\
\hline \multicolumn{10}{|l|}{ Concerns for missing friends } \\
\hline Bangladesh $(n=1599)$ & $1300(81.30)$ & $568(81.03)$ & $732(81.51)$ & 1.00 & $1.03(0.78,1.36)$ & 0.82 & 1.00 & $1.03(0.79,1.34)$ & 0.84 \\
\hline India $(n=5595)$ & $3821(68.29)$ & $1737(67.72)$ & $2084(68.78)$ & 1.00 & $1.05(0.94,1.17)$ & 0.39 & 1.00 & $1.05(0.94,1.18)$ & 0.39 \\
\hline Indonesia $(n=812)$ & $170(20.94)$ & $60(20.55)$ & $110(21.15)$ & 1.00 & $1.04(0.74,1.45)$ & 0.83 & 1.00 & $1.02(0.72,1.44)$ & 0.93 \\
\hline Myanmar $(n=386)$ & $108(27.98)$ & $42(25.61)$ & $66(29.73)$ & 1.00 & $1.23(0.79,1.90)$ & 0.36 & 1.00 & $1.23(0.80,1.91)$ & 0.35 \\
\hline Philippines $(n=421)$ & $208(49.41)$ & $86(48.04)$ & $122(50.41)$ & 1.00 & $1.10(0.70,1.73)$ & 0.68 & 1.00 & $1.04(0.67,1.62)$ & 0.85 \\
\hline Vietnam $(n=3419)$ & $1521(44.53)$ & $755(45.81)$ & $766(43.33)$ & 1.00 & $0.90(0.78,1.04)$ & 0.17 & 1.00 & $0.90(0.78,1.04)$ & 0.16 \\
\hline \multicolumn{10}{|c|}{ Concerns for household income / food security } \\
\hline Bangladesh $(n=1599)$ & $957(59.85)$ & $414(59.06)$ & $543(60.47)$ & 1.00 & $1.08(0.87,1.34)$ & 0.63 & 1.00 & $1.10(0.87,1.41)$ & 0.42 \\
\hline India $(n=5595)$ & $1601(28.61)$ & $697(27.17)$ & $904(29.83)$ & 1.00 & $1.14(1.01,1.29)$ & 0.040 & 1.00 & $1.13(1.00,1.28)$ & 0.049 \\
\hline Indonesia $(n=812)$ & $75(9.24)$ & $26(8.90)$ & $49(9.42)$ & 1.00 & $1.06(0.60,1.89)$ & 0.83 & 1.00 & $1.04(0.58,1.88)$ & 0.90 \\
\hline Myanmar $(n=386)$ & $80(20.73)$ & $29(17.68)$ & $51(22.97)$ & 1.00 & $1.39(0.83,2.34)$ & 0.22 & 1.00 & $1.43(0.80,2.54)$ & 0.23 \\
\hline Philippines $(n=421)$ & $119(28.27)$ & $40(22.35)$ & $79(32.64)$ & 1.00 & $1.68(0.99,2.87)$ & 0.06 & 1.00 & $1.59(0.93,2.71)$ & 0.09 \\
\hline Vietnam $(n=3419)$ & 469 (13.73) & $201(12.20)$ & $268(15.16)$ & 1.00 & $1.29(1.08,1.53)$ & 0.005 & 1.00 & $1.31(1.09,1.58)$ & 0.005 \\
\hline \multicolumn{10}{|l|}{ Feeling unsafe or insecure } \\
\hline Bangladesh $(n=1599)$ & $475(29.71)$ & $202(28.82)$ & $273(30.40)$ & 1.00 & $1.08(0.87,1.34)$ & 0.50 & 1.00 & $1.10(0.88,1.37)$ & 0.40 \\
\hline India $(n=5595)$ & $566(10.12)$ & $249(9.71)$ & $317(10.46)$ & 1.00 & $1.09(0.87,1.35)$ & 0.46 & 1.00 & $1.08(0.87,1.34)$ & 0.49 \\
\hline Indonesia $(n=812)$ & $116(14.29)$ & $41(14.04)$ & $75(14.42)$ & 1.00 & $1.03(0.65,1.63)$ & 0.89 & 1.00 & $1.01(0.65,1.58)$ & 0.95 \\
\hline Myanmar $(n=386)$ & $26(6.74)$ & $16(9.76)$ & $10(4.50)$ & 1.00 & $0.44(0.20,0.97)$ & 0.042 & 1.00 & $0.44(0.20,0.98)$ & 0.044 \\
\hline Philippines $(n=421)$ & $52(12.35)$ & $14(7.82)$ & $38(15.70)$ & 1.00 & $2.20(1.12,4.29)$ & 0.021 & 1.00 & $2.22(1.14,4.33)$ & 0.019 \\
\hline Vietnam $(n=3419)$ & 495 (14.49) & $217(13.17)$ & 278 (15.72) & 1.00 & $1.23(1.03,1.47)$ & 0.021 & 1.00 & $1.23(1.03,1.47)$ & 0.022 \\
\hline
\end{tabular}




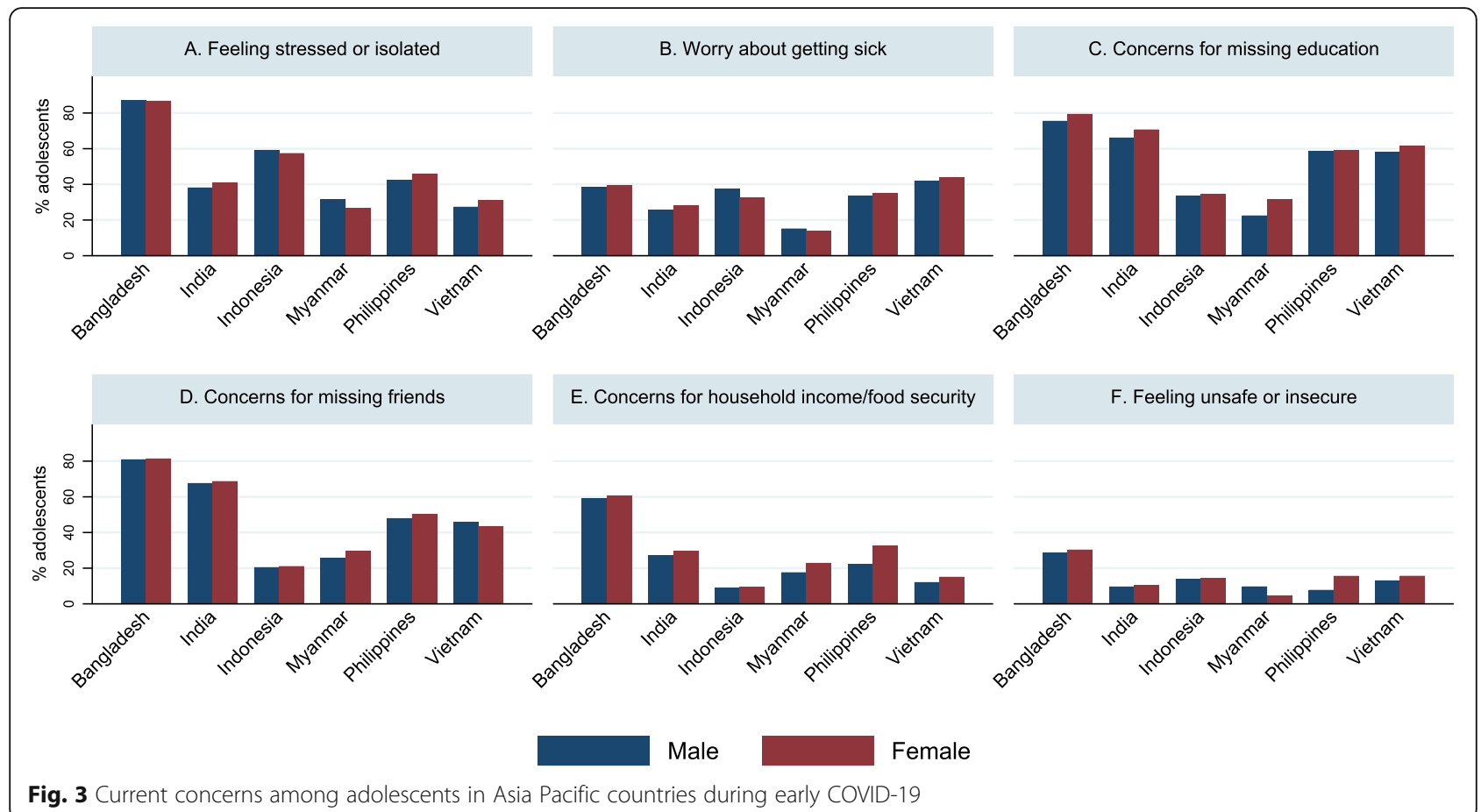

information acquisition, female adolescents were less likely than males to use internet/mobile phones to get COVID-19 related information, while they were more likely to use friends or family as information channels.

\section{Lack of access to distance learning across countries}

The present study showed strikingly low proportions of access to remote education or online courses across six countries, suggesting poor distance learning systems in these countries and poor access to these systems for vulnerable youths. Adolescents in resource-poor countries would be the most vulnerable learners during this global shock, due to a lack of accessibility to school materials and instruction required for distance learning during school closures [30]. Even before the pandemic, countries in the Asia Pacific Region were struggling with inequity of education issues [50]. From the beginning of lockdown measures in early 2020 until January 2021, the surveyed countries had experienced educational disruptions for more than one-third academic year on average: Bangladesh with 38 weeks, India with 47 weeks, Indonesia with 39 weeks, Myanmar with 39 weeks, the Philippines with 27 weeks, and Vietnam with 12 weeks [49]. The disruption of education can jeopardize not only adolescent's education and academic progress, but also physical safety and mental health in the short- and long-term. If there is not rapid and effective remediation, the loss of learning in these foundational years will increase the learning gaps in subsequent years, and increase drop-out rates [51]. The school closures, along with the pandemic's economic impacts, might affect parents' decisions regarding their child's education, and could potentially cost children the opportunity to complete their education, subsequently deepening the education equity gaps that existed before the pandemic [52]. In some Asian countries, male children are considered first for educational opportunities compared to their female siblings [32, 33], which may leave school-aged females with even more reduced access to education and higher drop-out rates during and after the pandemic compared to male counterparts. Dropping out of school may also increase the rate of child marriage and early pregnancies [53].

Our findings showed significant gender differences in study activities only in Vietnam, with female adolescents having higher odds ratio for studying at home than males. This may be attributed to the efforts of Vietnamese government to improve gender equity in education in recent decades. However, even as the education gender gap has begun to close for primary education in Vietnam, challenges still remain, especially for minority groups, and in secondary and post-secondary education [54]. Taken together, in addition to considering how to provide adequate and appropriate education for all school-aged adolescents during and after pandemic, policy makers need to eliminate the gender inequity that may be enlarged by the education disruption.

\section{Lack of physical activity among female students}

Staying-at-home has increased sedentary behavior, limited access to public services, and decreased physical activity 


\section{A. Feeling stressed}

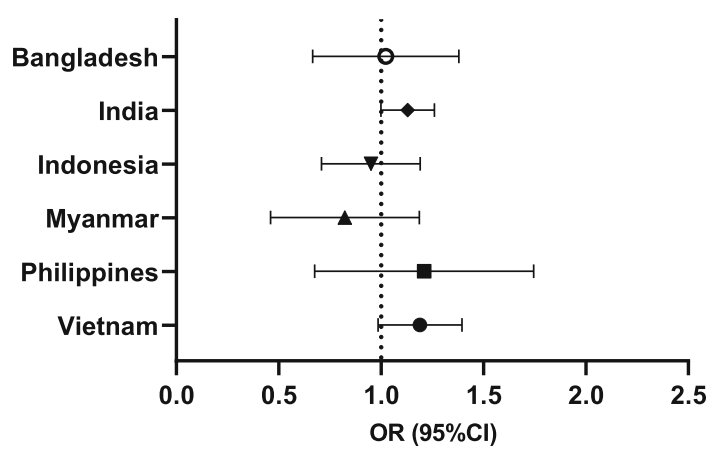

C. Concerns for missing education

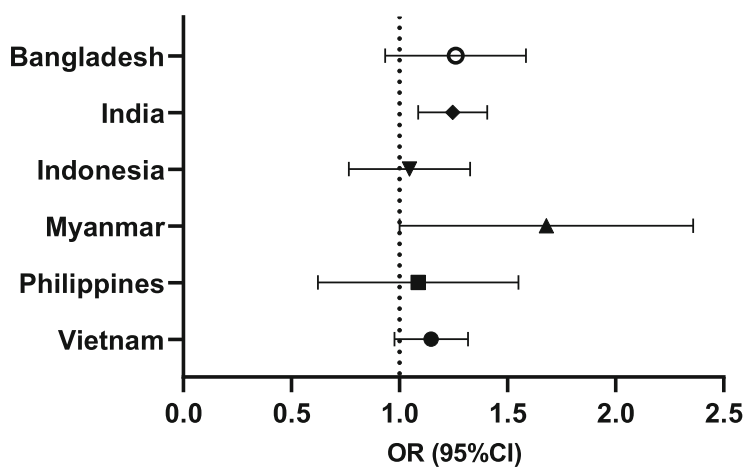

E. Concerns for household income

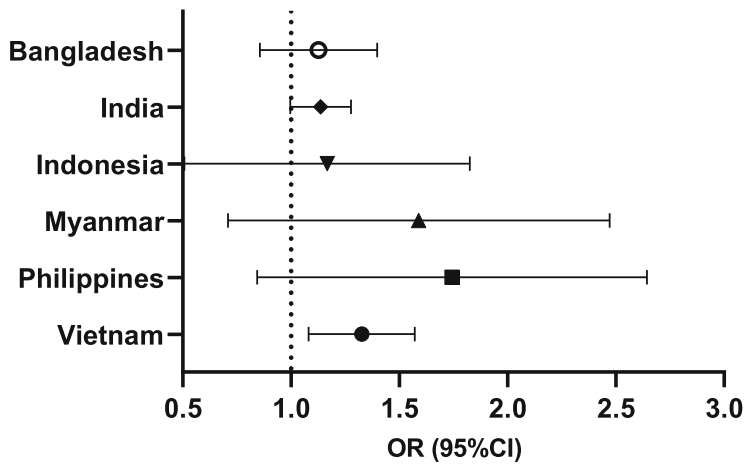

B. Worry about getting sick

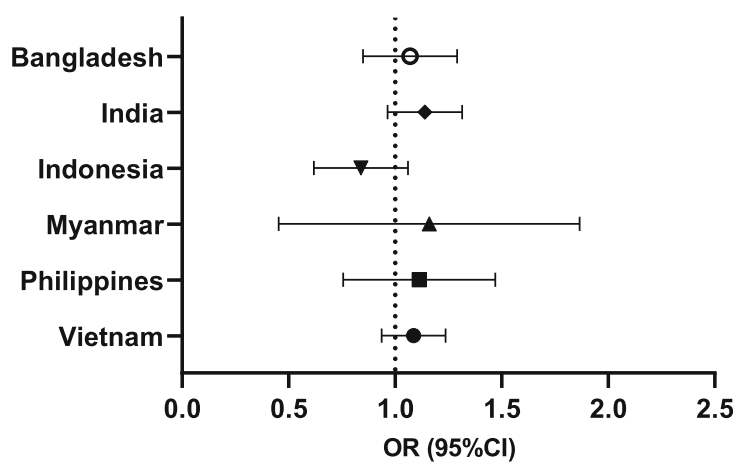

D. Concerns for missing friends

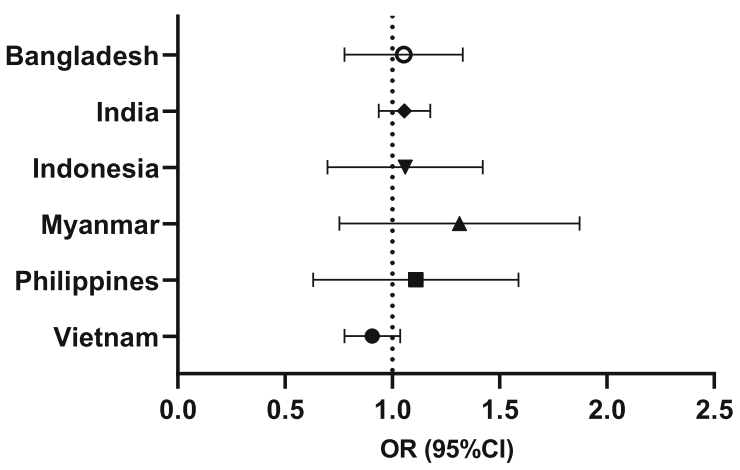

\section{F. Feeling unsafe or insecure}

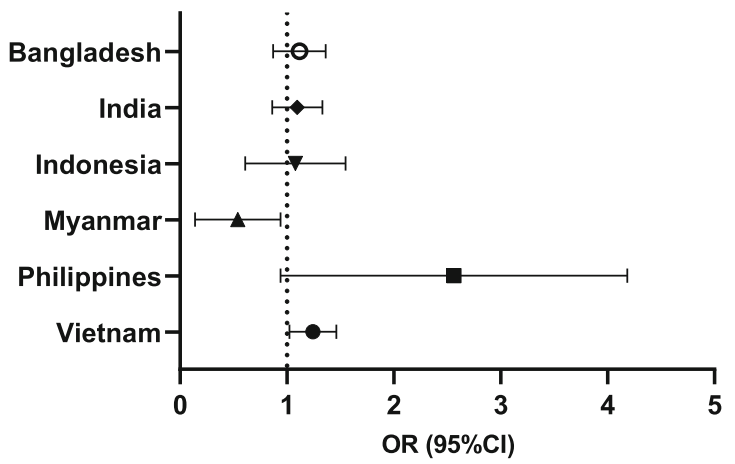

Fig. 4 Associations between adolescent gender and current concerns in Asia Pacific countries during early COVID-19

for both female and male youth, which has been associated with a higher risk of impeding adolescent mental and physical health and social-emotional development [30, 55, 56]. The present study revealed a lack of physical activities among female adolescents relative to males in five countries except for Indonesia. Our findings on physical activity supported previous studies before the COVID-19 pandemic began which showed that adolescent girls participate less in physical activities than their male counterparts in countries like India and Bangladesh $[57,58]$. The reasons for these gender differences could be that male adolescents demonstrated greater self-efficacy in overcoming barriers to physical activities and higher levels of participation in community physical activities [59]. Moreover, 
Table 4 Logistic regressions of adolescent gender for COVID-19 information sources in Asia Pacific countries

\begin{tabular}{|c|c|c|c|c|c|c|c|c|c|}
\hline & $\begin{array}{l}\text { Total } \\
\text { n (\%) }\end{array}$ & $\begin{array}{l}\text { Male } \\
\text { n (\%) }\end{array}$ & $\begin{array}{l}\text { Female } \\
\text { n (\%) }\end{array}$ & $\begin{array}{l}\text { Male } \\
\text { COR }\end{array}$ & $\begin{array}{l}\text { Female } \\
\text { COR }(95 \% \mathrm{Cl})\end{array}$ & $p$ value & $\begin{array}{l}\text { Male } \\
\text { AOR }\end{array}$ & $\begin{array}{l}\text { Female } \\
\text { AOR }(95 \% \mathrm{Cl})\end{array}$ & $p$ value \\
\hline \multicolumn{10}{|l|}{ Television } \\
\hline Bangladesh $(n=1599)$ & $1408(88.06)$ & $610(87.02)$ & $798(88.86)$ & 1.00 & $1.19(0.85,1.66)$ & 0.30 & 1.00 & $1.17(0.84,1.62)$ & 0.35 \\
\hline India $(n=5595)$ & $4401(78.77)$ & $2012(78.44)$ & $2395(79.04)$ & 1.00 & $1.04(0.91,1.18)$ & 0.58 & 1.00 & $1.03(0.91,1.18)$ & 0.61 \\
\hline Indonesia $(n=812)$ & $601(74.01)$ & $222(76.03)$ & 379 (72.88) & 1.00 & $0.85(0.62,1.17)$ & 0.31 & 1.00 & $0.84(0.61,1.16)$ & 0.29 \\
\hline Myanmar $(n=386)$ & $290(75.13)$ & $120(73.17)$ & $170(76.58)$ & 1.00 & $1.20(0.75,1.91)$ & 0.45 & 1.00 & $1.22(0.76,1.97)$ & 0.41 \\
\hline Philippines $(n=421)$ & 362 (85.99) & 156 (87.15) & $206(85.12)$ & 1.00 & $0.84(0.46,1.53)$ & 0.58 & 1.00 & $0.83(0.45,1.54)$ & 0.55 \\
\hline Vietnam $(n=3419)$ & $2556(74.82)$ & $1209(73.36)$ & $1347(76.19)$ & 1.00 & $1.16(0.95,1.42)$ & 0.14 & 1.00 & $1.17(0.95,1.43)$ & 0.13 \\
\hline \multicolumn{10}{|l|}{ Internet/social media } \\
\hline Bangladesh $(n=1599)$ & $751(46.97)$ & 396 (56.49) & 355 (39.53) & 1.00 & $0.50(0.40,0.64)$ & $<0.001$ & 1.00 & $0.51(0.41,0.64)$ & $<0.001$ \\
\hline India $(n=5595)$ & $2342(41.86)$ & $1127(43.94)$ & $1215(40.10)$ & 1.00 & $0.85(0.75,0.97)$ & 0.019 & 1.00 & $0.84(0.73,0.96)$ & 0.010 \\
\hline Indonesia $(n=812)$ & $292(35.96)$ & $103(35.27)$ & 189 (36.35) & 1.00 & $1.05(0.74,1.49)$ & 0.80 & 1.00 & $1.07(0.76,1.51)$ & 0.70 \\
\hline Myanmar $(n=386)$ & $107(27.72)$ & $54(32.93)$ & $53(23.87)$ & 1.00 & $0.64(0.42,0.97)$ & 0.034 & 1.00 & $0.65(0.43,0.97)$ & 0.036 \\
\hline Philippines $(n=421)$ & $238(56.53)$ & $86(48.04)$ & $152(62.81)$ & 1.00 & $1.83(1.30,2.58)$ & 0.001 & 1.00 & $1.85(1.27,2.70)$ & 0.001 \\
\hline Vietnam $(n=3419)$ & $2307(67.54)$ & $1106(67.11)$ & $1201(67.93)$ & 1.00 & $1.04(0.87,1.24)$ & 0.68 & 1.00 & $1.06(0.89,1.27)$ & 0.50 \\
\hline \multicolumn{10}{|l|}{ Mobile (phone call/SMS) } \\
\hline Bangladesh $(n=1599)$ & $947(59.22)$ & 407 (58.06) & $540(60.13)$ & 1.00 & $1.09(0.85,1.39)$ & 0.49 & 1.00 & $1.12(0.88,1.43)$ & 0.35 \\
\hline India $(n=5595)$ & $3581(64.00)$ & $1677(65.38)$ & $1904(62.84)$ & 1.00 & $0.90(0.82,0.98)$ & 0.020 & 1.00 & $0.88(0.80,0.98)$ & 0.014 \\
\hline Indonesia $(n=812)$ & $132(16.26)$ & $51(17.47)$ & $81(15.58)$ & 1.00 & $0.87(0.58,1.31)$ & 0.51 & 1.00 & $0.83(0.56,1.23)$ & 0.35 \\
\hline Myanmar $(n=386)$ & $50(12.95)$ & $24(14.63)$ & $26(11.71)$ & 1.00 & $0.77(0.46,1.29)$ & 0.33 & 1.00 & $0.79(0.48,1.29)$ & 0.35 \\
\hline Philippines $(n=421)$ & $70(16.63)$ & $25(13.97)$ & $45(18.60)$ & 1.00 & $1.41(0.79,2.49)$ & 0.24 & 1.00 & $1.40(0.77,2.55)$ & 0.28 \\
\hline Vietnam $(n=3419)$ & $1797(52.61)$ & 839 (50.91) & $958(54.19)$ & 1.00 & $1.14(0.98,1.33)$ & 0.10 & 1.00 & $1.15(0.98,1.35)$ & 0.08 \\
\hline \multicolumn{10}{|l|}{ Friends } \\
\hline Bangladesh $(n=1599)$ & 665 (41.59) & $300(42.80)$ & $365(40.65)$ & 1.00 & $0.92(0.76,1.10)$ & 0.35 & 1.00 & $0.96(0.80,1.15)$ & 0.63 \\
\hline India $(n=5595)$ & $2991(53.46)$ & $1385(54.00)$ & $1606(53.00)$ & 1.00 & $0.96(0.86,1.07)$ & 0.47 & 1.00 & $0.96(0.86,1.06)$ & 0.41 \\
\hline Indonesia $(n=812)$ & $181(22.29)$ & $64(21.92)$ & $117(22.50)$ & 1.00 & $1.03(0.75,1.42)$ & 0.84 & 1.00 & $1.07(0.78,1.47)$ & 0.67 \\
\hline Myanmar $(n=386)$ & $98(25.39)$ & $39(23.78)$ & $59(26.58)$ & 1.00 & $1.16(0.70,1.91)$ & 0.56 & 1.00 & $1.17(0.71,1.94)$ & 0.54 \\
\hline Philippines $(n=421)$ & $42(9.98)$ & $22(12.29)$ & $20(8.26)$ & 1.00 & $0.64(0.30,1.36)$ & 0.25 & 1.00 & $0.56(0.26,1.22)$ & 0.14 \\
\hline Vietnam $(n=3419)$ & $1749(51.20)$ & 809 (49.09) & $940(53.17)$ & 1.00 & $1.18(1.02,1.36)$ & 0.030 & 1.00 & $1.18(1.02,1.36)$ & 0.029 \\
\hline \multicolumn{10}{|l|}{ Family } \\
\hline Bangladesh $(n=1599)$ & $945(59.10)$ & 377 (53.78) & $568(63.25)$ & 1.00 & $1.48(1.24,1.77)$ & $<0.001$ & 1.00 & $1.44(1.21,1.70)$ & $<0.001$ \\
\hline India $(n=5595)$ & $3439(61.47)$ & $1495(58.28)$ & $1944(64.16)$ & 1.00 & $1.28(1.14,1.43)$ & $<0.001$ & 1.00 & $1.29(1.15,1.45)$ & $<0.001$ \\
\hline Indonesia $(n=812)$ & $305(37.56)$ & $106(36.30)$ & 199 (38.27) & 1.00 & $1.09(0.78,1.51)$ & 0.62 & 1.00 & $1.07(0.77,1.50)$ & 0.67 \\
\hline Myanmar $(n=386)$ & $164(42.49)$ & $70(42.68)$ & $94(42.34)$ & 1.00 & $0.99(0.65,1.49)$ & 0.95 & 1.00 & $0.97(0.64,1.47)$ & 0.89 \\
\hline Philippines $(n=421)$ & $115(27.32)$ & $56(31.28)$ & $59(24.38)$ & 1.00 & $0.71(0.42,1.21)$ & 0.20 & 1.00 & $0.72(0.42,1.24)$ & 0.23 \\
\hline Vietnam $(n=3419)$ & $1989(58.23)$ & $947(57.46)$ & $1042(58.94)$ & 1.00 & $1.06(0.93,1.21)$ & 0.36 & 1.00 & $1.06(0.93,1.21)$ & 0.38 \\
\hline
\end{tabular}

AOR models were adjusted by type of community (rural vs. urban) and adolescents age (years)

in India, the barriers for female youth also included negative body image and social censure by participating in physical activities [57]. In many Asian countries, it is more culturally and socially acceptable for boys to participate in formal organized sports and group physical activities than for girls [57].

\section{Higher vulnerability to psychosocial distress among females}

Findings in the current study indicated that large proportions of respondents felt boredom or missed friends during the lockdown. Schools are the primary social venues for school-aged adolescents; thus, the closure of schools has cut off channels for interaction, and thrust 
them into social isolation [60], which could have longterm negative effects on mental health [61]. Apart from the school closures, other collateral effects that come with the lockdown may also influence adolescent psychosocial status and result in a high rates of COVID-19 related stress among the respondents in this study. Previous studies showed that having relatives or neighbors who had tested positive for diseases, like the H1N1 or COVID-19, may increase fears of illness and death among children $[62,63]$.

The present study showed that females are more vulnerable under stress caused by COVID-19. Previous evidence reported that, globally, female adolescents were more likely to have negative emotions and higher levels of psychological distress than their male counterparts during the COVID-19 pandemic [13, 20, 64-68]. Gender differences, such as higher sensitivity to traumatic events, may contribute to the higher level and prevalence of psychological morbidity among females than males [69]. Higher level of stress faced by female adolescents than their male peers in Asia Pacific countries may also be attributed to socio-economic stressors. For example, past evidence from India suggested that girls are more likely to be pushed into the labor market to compensate for economic loss of the family caused by COVID-19 restrictions [35]. In addition, the restrictions increased the risk of domestic or sexual abuse in South Asia among young females, especially those in extreme poverty [70].

Given the negative impacts brought by the restriction measures and COVID-19 pandemic itself, it calls for timely interventions to address adolescents' psychosocial needs. Psychosocial distress experienced by adolescents, if abandoned, will also impede their physical and mental health in their adulthood [27]. Policy makers and social organizations need to aware that female adolescents may face more complicated situations, while developing and implementing such interventions in the region.

\section{Different information resources for COVID-19 by gender}

Accessing to COVID-19 information is important for adolescents to get adequate knowledge of COVID-19. Such knowledge was proved to be significantly associated with COVID-19 related risk perception and practicing protective behaviors among dental students in India [28, 71]. In our study, female adolescents were more likely to get COVID-19- related information from family or friends and had less access to the internet or mobile phones, compared to male adolescents. This gender disparity could be explained by existing gender disparities in accessing to mobile and internet in these countries. According to the Mobile Gender Gap Report [72], Bangladesh had the highest gender gap in Asian countries surveyed, where $58 \%$ of adult women were less likely to use mobile internet than males, followed by
India (56\%), Myanmar (39\%), and Indonesia (18\%), respectively. Evidence showed that the Philippines made great progress in making the internet accessible to females [73], which may contribute to the outcome that the female adolescents were more likely to have COVID-19 information via internet than males in the Philippines. Getting access to internet could increase adolescents' perceptions of inclusiveness [71], thereby it has salient implications to adolescents' mental health during COVID-19. By and large, due to less access to open information sources (i.e., internet), female adolescents may get less exposure to means that could support their physical and mental health.

\section{Implications}

Evidence-based response and recovery interventions are a top necessity to help reduce adverse psychosocial impacts on adolescents. This study demonstrates that female adolescents have different psychosocial needs than their male peers, shows how these needs may have changed due to the pandemic, and how these needs depend on culture and context. Our findings have implications for social support, policy making by governments, and planning post-pandemic response and recovery strategies by organizations, like UNICEF.

First, alternative academic supports are urgently needed to improve education opportunities and life quality for affected adolescents from low-income Asian countries. It is a challenge to prepare facilities and techniques for remote education on a large scale in a short period of time. Thus, governments of the surveyed countries have already taken measures to compensate $\mathrm{K}-12$ education service. For instance, Bangladesh applied a multi-modal approach including television, radio, internet, and mobile phones [74]. A survey conducted in the Philippines showed only $64 \%$ students are willing to engage in distance learning via computer or other digital devices [75]. Hence, the coverage rate and effectiveness of such models still need to be monitored and evaluated, especially in rural areas.

Second, psychosocial interventions for adolescents should extend to the community and family, considering the local cultural characteristics, focusing on gender difference. For example, nationwide community healthcare networks, such as Bangladesh Rural Advancement Committee (BRAC) in Bangladesh, could be utilized to deliver services to the remotest areas [76]. As most people in the Asia Pacific region are religious, understanding local religious culture and cooperating with local health workers or faith leaders would help policy makers and social organizations to better identify the psychosocial needs of adolescents. In addition, with the increasing challenges faced by families, parents' emotional resources are drained, and their parenting capacity is 
reduced [77]. Plus, the level of social support was suggested to be inversely associated with prevalence of depression and anxiety symptoms among adolescents [65], with parental support being the most important source of social support in adolescent life [78]. However, such evidence is lacking among the surveyed six countries.

Third, beyond academic and psychosocial support at a general population level, the recovery efforts from policy makers and social organizations should provide more specific and safety COVID-related information services for adolescents in Asia Pacific countries. As mentioned previously, information accuracy and transparency will reduce the uncertainty and fear of the virus and lockdown policies. It is important to analyze the sources where adolescents frequently seek information to understand how we can disseminate sufficient and effective information to them. Our findings suggested that the channels of receiving COVID-19 related information differ by child gender. This suggest that the COVID-19 information channels need to be diversified considering gender sensitivity. Public health organizations may have a larger presence on television outlets versus social media [79]. Actively utilizing mass media channels like $\mathrm{TV}$, social media, and mobile-phone texts could be part of future strategies for rapid knowledge dissemination related to COVID-19. More attention should be paid to female adolescents to mitigate the gender disparities brought by information bias.

Fourth, follow-up investigations and strategies should be developed considering the possibilities of increased incidence of Post-Traumatic Stress Disorder (PTSD) or Post-Traumatic Stress Symptoms (PTSS) in the ongoing and post-pandemic phases. PTSD and PTSS have been reported among adolescents after traumatic events like the Gorkha earthquake in Nepal [80] and the Ebola and SARS outbreaks [81, 82]. An increased prevalence of PTSS, as a result of the COVID-19 pandemic, was already found among residents [83] and youth [84] in the hardest-hit areas in China. The limited literature in the region has identified clear gaps between the mental health services available and the demand $[63,85,86]$. Thus, to cope with a potential rise in PTSS among adolescents during and after the pandemic, recovery strategies need to be analyzed by public health organizations to ensure that they include interventions and mechanisms to help adolescents deal with PTSS.

\section{Limitations}

There are several limitations to the present study. First, the sampling strategy varied in its detail by country. This can limit the representativeness of vulnerable adolescents in the World Vision's program areas. The structure of the survey sampling frames varied by country and the regional aggregated data were not weighted to the survey population. Another limitation is nonprobabilistic sampling, as most of the data collection occurred in areas supported by long-term development or COVID-19 relief support agencies. This selective choice of survey participants does not guarantee the generalizability of the findings.

Second, the child survey questionnaire had no information on the parent's or caregiver's occupation, education level, and other socioeconomic indicators. These are potential confounders related to our outcome variables. Thus, the regression analysis only accounted for rural and urban residence and child age.

Third, this study employed a self-report survey, which is more likely to introduce response bias. It would be more comprehensive to conduct analysis by integrating perceptions from both adolescents and parents in future research.

Fourth, the cross-sectional survey does not provide information prior to COVID-19 pandemic. Findings regarding lack of access to education or physical activities are therefore not solely due to the COVID-19 pandemic, but instead could be mixed with existing gaps before COVID-19.

Thus, it is also necessary to conduct a prospective longitudinal study to look deeper at the predictive indicators of adolescent psychosocial status within the context of COVID-19 over time, as the pandemic and subsequent recovery period progress.

Fifth, the surveyed adolescents were receiving different levels of assistance from World Vision and possibly other organizations. Also, the survey was conducted by World Vision staff or community members, which could introduce desirability bias among respondents.

\section{Conclusion}

During the early stages of the COVID-19 pandemic, adolescents in the Asia Pacific region are considered at a high risk in terms of receiving education and facing gender inequity. It is important to understand their current situation to support policy makers and associated organizations come up with response and recovery actions to mitigate the negative impacts caused by the restrictions. Our findings revealed that surveyed adolescents in six countries in the Asia Pacific region were experiencing a severe disruption of education and lack of access to distance learning. During the first year of the pandemic, the physical and psychosocial status of female youth were more negatively affected than male peers. Considering the possibilities of posttraumatic symptoms, longitudinal research is needed to understand the long-term impact of COVID-19 on psycho-social status among adolescents in the region. In addition, future research could investigate support to parents on parenting, home-schooling, and mental health that would bolster parents' well-being 
so as to ultimately mitigate adolescents' psychological distress. Alongside, public health services need to be prepared for long-term mental health supports, particularly for female adolescents. Also, public health services should extend social support to community and family levels, and integrate mass media in information dissemination.

\section{Abbreviations}

AOR: Adjusted Odds Ratio; AP: Area Programmes; BRAC: Bangladesh Rural Advancement Committee; Cl: Confidence Intervals; OR: Odds Ratio; PTSD: Post-Traumatic Stress Disorder; PTSS: Post-Traumatic Stress Symptoms; SARS: Severe Acute Respiratory Syndrome; TV: Television; UN: United Nations; UNESCO: United Nations Educational, Scientific and Cultural Organization; US: United States; W: World Vision

\section{Supplementary Information}

The online version contains supplementary material available at https://doi. org/10.1186/s12889-021-12098-5.

\section{Additional file 1}

\section{Acknowledgements}

All authors thank World Vision Asia Pacific Regional Office and World Vision US for kindly providing administrative support, including data sharing. We acknowledge the World Vision National Offices (Bangladesh, India, Indonesia, Myanmar, the Philippines, and Vietnam) for data collection, management, and sharing. We also thank Alodia Santos, and Leen Decadt from W International and Holta Trandafili from World Vision US for their technical review of the manuscript and administrative support to this research. We thank Soim Park for her kind review of the manuscript.

\section{Authors' contributions}

JW data analysis, data interpretation, and preparation of manuscript; AA and $A B$ preparation of manuscript and review of manuscript; $C C$ and $E W$ management, supervision, and editing and review of manuscript; KS and MJ data interpretation and editing and review of manuscript; YK study concept and design, methodology, management, editing and review of manuscript. All authors read and approved the final manuscript.

\section{Funding}

This research received no grant from any funding agency in the public commercial or not-for-profit sectors.

\section{Availability of data and materials}

The data that support the findings of this study are available from World Vision, but restrictions apply to the availability of these data, which were used under license for the current study, and so are not publicly available. Data are however available from the authors upon reasonable request and with permission of World Vision.

\section{Declarations}

\section{Ethics approval and consent to participate}

This study is a secondary analysis of data drawn from a set of surveys of adolescent children conducted by World Vision International as part of a multi-country "Rapid Recovery Assessment". Informed consents have been obtained from all the study participants. World Vision did not get the approval from Ethical committee as the survey was conducted under emergency response support. Johns Hopkins School of Public Health has ethics committee to exempt the need of ethical approval for this study. The study team (Yunhee Kang, PI) received administrative permission to access the data from World Vision Asia Pacific Regional Office.

\section{Consent for publication}

Not applicable.

\section{Competing interests}

The authors declare that they have no competing interests.

\section{Author details}

${ }^{1}$ Johns Hopkins School of Education, Baltimore, MD, USA. ${ }^{2}$ Johns Hopkins Bloomberg School of Public Health, Baltimore, MD, USA. ${ }^{3}$ World Vision Asia Pacific Regional Office, Singapore, Republic of Singapore. ${ }^{4}$ World Vision United States, Federal Way, WA, USA. 'World Vision International, Geneva, Switzerland.

Received: 5 May 2021 Accepted: 20 October 2021

Published online: 04 November 2021

\section{References}

1. Hsiang S, Allen D, Annan-Phan S, Bell K, Bolliger I, Chong T, et al. The effect of large-scale anti-contagion policies on the COVID-19 pandemic. Nature (London). 2020;584(7820):262-7. https://doi.org/10.1038/s41586-020-2404-8.

2. World Health Organization. WHO Coronavirus (COVID-19) Dashboard. Available at: https://covid19.who.int. Accessed Oct 122021.

3. United Nations Office for the Coordination of Humanitarian Affairs. Impact of the Crisis. Available at: https://interactive.unocha.org/data/ap-covid19portal/impact-crisis.html. Accessed 30 Sept 2021.

4. Zhang SX, Chen J, Jahanshahi AA, Alvarez-Risco A, Dai H, Li J, et al. Succumbing to the COVID-19 pandemic-healthcare workers not satisfied and intend to leave their jobs. Int J Ment Heal Addict. 2021:1-10. https:// doi.org/10.1007/s11469-020-00418-6.

5. Yan J, Kim S, Zhang SX, Foo M, Alvarez-Risco A, Del-Aguila-Arcentales S, et al. Hospitality workers' COVID-19 risk perception and depression: a contingent model based on transactional theory of stress model. Int J Hosp Manag. 2021;95:102935. https://doi.org/10.1016/j.ijhm.2021.102935.

6. Thatrimontrichai A, Weber DJ, Apisarnthanarak A. Mental health among healthcare personnel during COVID-19 in Asia: a systematic review. J Formos Med Assoc. 2021;120(6):1296-304. https://doi.org/10.1016/j.fma.2 021.01.023.

7. Lai J, Ma S, Wang Y, Cai Z, Hu J, Wei N, et al. Factors associated with mental health outcomes among health care workers exposed to coronavirus disease 2019. JAMA Netw Open. 2020;3(3):e203976. https://doi.org/10.1001/ jamanetworkopen.2020.3976

8. Razali S, Abdullah MN, Rahman NA, Azhar NA, Yaacob SS. Psychological distress of health Care Workers in the Main Admitting Hospital and its Related Health Care Facilities in Malaysia during the COVID-19 pandemic. Asia Pac J Public Health. 2021;33(5):667-9. https://doi.org/10.1177/101053 95211014348

9. Tan BYQ, Chew NWS, Lee GKH, Jing M, Goh Y, Yeo LLL, et al. Psychological impact of the COVID-19 pandemic on health Care Workers in Singapore. Ann Intern Med. 2020;173(4):317-20. https://doi.org/10.7326/M20-1083.

10. Alvarez-Risco A, Mlodzianowska S, García-lbarra V, Rosen MA, Del-AguilaArcentales S. Factors Affecting Green Entrepreneurship Intentions in Business University Students in COVID-19 Pandemic Times: Case of Ecuador. Sustainability (Basel, Switzerland). 2021;13(11):6447.

11. Alkwiese M, Alsaqri SH, Aldalaykeh M, Hamzi M, Mahdi M, Shafie Z. Anxiety among the general population during Coronavirus-19 disease in Saudi Arabia: implications for a mental support program. Medical Letter on the CDC \& FDA 2020:189.

12. Kassaw $C$. The magnitude of psychological problem and associated factor in response to COVID-19 pandemic among communities living in Addis Ababa, Ethiopia, march 2020: a cross-sectional study design. Psychol Res Behav Manag. 2020;13:631-40. https://doi.org/10.2147/PRBM.S256551.

13. Wang C, Pan R, Wan X, Tan Y, Xu L, Ho CS, et al. Immediate psychological responses and associated factors during the initial stage of the 2019 coronavirus disease (COVID-19) epidemic among the general population in China. Int J Environ Res Public Health. 2020;17(5):1729. https://doi.org/10.33 90/ijerph17051729.

14. Czeisler MÉ, Lane RI, Petrosky E, Wiley JF, Christensen A, Njai R, et al. Mental health, substance use, and suicidal ideation during the COVID-19 pandemic - United States, June 24-30, 2020. MMWR Morb Mortal Wkly Rep. 2020; 69(32):1049-57. https://doi.org/10.15585/mmwr.mm6932a1.

15. Alessi J, de Oliveira GB, Feiden G, Schaan BD, Telo GH. Caring for caregivers: the impact of the COVID-19 pandemic on those responsible for children and adolescents with type 1 diabetes. Sci Rep. 2021:11(1):6812. https://doi. org/10.1038/s41598-021-85874-3. 
16. UNESCO. UNESCO education: From disruption to recovery. Available at: https:/en.unesco.org/covid19/educationresponse. Accessed 26 Jan 2021.

17. Alvarez-Risco A, Estrada-Merino A, Anderson-Seminario MM, Mlodzianowska S, García-lbarra V, Villagomez-Buele C, et al. Multitasking Behavior in Online Classrooms and Academic Performance: Case of University Students in Ecuador During COVID-19 Outbreak. Inter Technol Smart Education. 18(3): 422-34

18. Saavedra J. Educational challenges and opportunities of the coronavirus (COVID-19) pandemic. 2020. Available at: https://blogs.worldbank.org/educa tion/educational-challenges-and-opportunities-covid-19-pandemic. Accessed 15 Jan 2021.

19. Loon V, Amanda WG, Creemers HE, Vogelaar S, Saab N, Miers AC, et al. The Effectiveness of School-Based Skills-Training Programs Promoting Mental Health in Adolescents: A Study Protocol For A Randomized Controlled Study. BMC Public Health. 2019:19(1):712.

20. Batra K, Sharma M, Batra R, Singh TP, Schvaneveldt N. Assessing the psychological impact of COVID-19 among college students: an evidence of 15 countries. Healthcare (Basel). 2021;9(2):222. https://doi.org/10.3390/hea Ithcare9020222.

21. Brooks SK, Webster RK, Smith LE, Woodland L, Wessely S, Greenberg N, et al. The psychological impact of quarantine and how to reduce it: rapid review of the evidence. Lancet (British edition). 2020;395(10227):912-20.

22. Pietrabissa G, Volpi C, Bottacchi M, Bertuzzi V, Guerrini Usubini A, LöfflerStastka $\mathrm{H}$, et al. The impact of social isolation during the COVID-19 pandemic on physical and mental health: the lived experience of adolescents with obesity and their caregivers. Int J Environ Res Public Health. 2021;18(6):3026. https://doi.org/10.3390/ijerph18063026.

23. Brown SM, Doom JR, Lechuga-Peña S, Watamura SE, Koppels T. Stress and parenting during the global COVID-19 pandemic. Child Abuse Negl. 2020; 110(Pt 2):104699. https://doi.org/10.1016/j.chiabu.2020.104699.

24. Griffith AK. Parental burnout and child maltreatment during the COVID-19 pandemic. J Fam Violence. 2020:1-7. https://doi.org/10.1007/s10896-020-001 $72-2$.

25. Juneja A, Singh N, Sultan A, Juneja A. Negative impact of COVID-19 on the lives of children: an Indian perspective. J Adv Sci Res. 2020;11(Suppl 3):44-8.

26. Power E, Hughes S, Cotter D, Cannon M. Youth mental health in the time of COVID-19. Ir J Psychol Med. 2020;37(4):301-5. https://doi.org/10.1017/ipm.2 020.84 .

27. World Health Organization. Adolescent mental health. Available at: https:// www.who.int/news-room/fact-sheets/detail/adolescent-mental-health. Accessed 30 Sept 2021.

28. Batra K, Urankar Y, Batra R, Gomes AF, Meru S, Kaurani P. Knowledge, Protective Behaviors and Risk Perception of COVID-19 among Dental Students in India: A Cross-Sectional Analysis. Healthcare (Basel). 2021;9(5): 574.

29. Sharma M, Batra K, Davis RE, Wilkerson AH. Explaining handwashing behavior in a sample of college students during COVID-19 pandemic using the multi-theory model (MTM) of health behavior change: a single institutional cross-sectional survey. Healthcare (Basel). 2021;9(1):55. https:// doi.org/10.3390/healthcare9010055.

30. United Nations. Policy Brief: Education during COVID-19 and beyond. United Nations 2020. Available at: https://www.un.org/development/desa/dspd/wpcontent/uploads/sites/22/2020/08/sg_policy_brief_covid-19_and_educa tion_august_2020.pdf. Accessed 20 Dec 2020.

31. Burzynska K, Contreras G. Gendered Effects of School Closures During the COVID-19 Pandemic. Lancet (British edition). 2020;395(10242):1968.

32. Ferdaush J, Rahman K. Gender Inequality in Bangladesh. 2011. Available at: https://archive.nyu.edu/jspui/bitstream/2451/33900/2/gender_inequality_in_ bangladesh.pdf. Accessed 26 Jan 2021.

33. White G, Ruther M, Kahn J. Educational Inequality in India: An Analysis of Gender Differences in Reading and Mathematics. 2015. Available at: https:// s3.amazonaws.com/drupal-base-s3-drupalshareds3-1 qwpjwcnqwwsr/ihds/s3 fs-public/WhiteRutherKahn.pdf. Accessed 15 Nov 2021.

34. Prakash $R$, Beattie $T$, Javalkar $P$, Bhattacharjee $P$, Ramanaik $S$, Thalinja $R$, et al. Correlates of School Dropout and Absenteeism Among Adolescent Girls from Marginalized Community in North Karnataka, South India. J Adolesc(London, England). 2017;61:64-76.

35. Alvi M, Gupta M. Learning in times of lockdown: how Covid-19 is affecting education and food security in India. Food Security. 2020;12(4):793-6. https://doi.org/10.1007/s12571-020-01065-4
36. Cooray A, Potrafke N. Gender inequality in education. Eur J Polit Econ. 2011; 27(2):268-80. https://doi.org/10.1016/j.ejpoleco.2010.08.004.

37. Ordaz S, Luna B. Sex differences in physiological reactivity to acute psychosocial stress in adolescence. Psychoneuroendocrinology. 2012;37(8): 1135-57. https://doi.org/10.1016/j.psyneuen.2012.01.002.

38. Matud MP. Gender differences in stress and coping styles. Personal Individ Differ. 2004;37(7):1401-15. https://doi.org/10.1016/j.paid.2004.01.010.

39. Chik H. Coronavirus: What Are the Lockdown Measures and Travel Bans in Asia? In: South China Morning Post (Online); 2020. Available at: https://www scmp.com/news/china/society/article/3078552/coronavirus-what-arelockdown-measures-and-travel-bans-asia. Accessed 30 Oct 2020.

40. CSIS. Southeast Asia Covid-19 Tracker. Available at: https://www.csis.org/ programs/southeast-asia-program/southeast-asia-covid-19-tracker-0. Accessed 15 Jan 2021.

41. Jones A. Coronavirus: How 'overreaction' made Vietnam a virus success. 2020. Available at: https://www.bbc.com/news/world-asia-52628283. Accessed 15 Nov 2020.

42. BBC. Coronavirus: Millions return to lockdown in Philippines. 2020. Available at: https://www.bbc.com/news/world-asia-53646149. Accessed 15 Jan 2021.

43. UNESCO. COVID-19 Educational Disruption and Response in Asia-Pacific. Available at: https://apa.sdg4education2030.org/covid19. Accessed 01 March 2021

44. Menon S. Coronavirus: How the lockdown has changed schooling in South Asia. BBC. 2020. Available at: https://www.bbc.com/news/world-south-asia54009306. Accessed 15 Nov 2020.

45. Lee YN. The pandemic's effect on education is not being discussed enough, says Indonesian minister. 2020. Available at: https://www.cnbc.com/2020/ 09/14/indonesias-education-minister-on-covids-effect-on-students-learning. html. Accessed 15 Nov 2020.

46. France-Presse A. Vietnam kids back at school after 3-month virus break. The Jakarta Post. 2020. Available at: https://www.thejakartapost.com/seasia/202 0/05/04/vietnam-kids-back-at-school-after-3-month-virus-break.html . Accessed 20 Dec 2020.

47. UN Myanmar. Back to school after COVID-19: Safe reopening of schools. 2020. Available at: https://myanmar.un.org/en/92061-responding-educationcrisis. Accessed 15 Jan 2021.

48. UN News. Learning lessons from COVID-19 in Myanmar. 2020. Available at: https://www.emis.com/php/search/doc?pc=MM\&dcid=693692309\&primo=1. Accessed 15 Jan 2021

49. UNESCO. UNESCO Figures Show Two Thirds of an Academic Year Lost on Average Worldwide Due to COVID-19 School Closures. 2021. Available at: https://en.unesco.org/news/unesco-figures-show-two-thirds-academic-yearlost-average-worldwide-due-covid-19-school. Accessed 26 Jan 2021.

50. Government of the People's Republic of Bangladesh Ministry of Primary and Mass Education Ministry of Education. COVID-19 Response and Recovery Plan, Education Sector. Government of the People's Republic of Bangladesh Ministry of Primary and Mass Education Ministry of Education 2020 Available at: https://planipolis.iiep.unesco.org/sites/default/files/ressources/ bangladesh_moe_covid_19_response_and_recovery_plan.pdf. Accessed 15 Jan 2021.

51. Kaffenberger M. Modelling the long-run learning impact of the Covid-19 learning shock: actions to (more than) mitigate loss. Int J Educ Dev. 2021;81: 102326. https://doi.org/10.1016/j.ijedudev.2020.102326.

52. Azevedo JP, Hasan A, Goldemberg D, labal SA, Geven K. Simulating the Potential Impacts of COVID-19 School Closures on Schooling and Learning Outcomes: A Set of Global Estimates. 2020. Available at: https:// openknowledge.worldbank.org/bitstream/handle/10986/33945/Simulatingthe-Potential-Impacts-of-COVID-19-School-Closures-on-Schooling-and-Lea rning-Outcomes-A-Set-of-Global-Estimates.pdf?sequence=1\&isAllowed=y. Accessed 15 Jan 2021.

53. Birchall J. Early Marriage, Pregnancy and Girl Child School Dropout. K4D 2018. Available at: https://assets.publishing.service.gov.uk/media/5c6ac3044 Of0b61a1afc3f7c/470_Early_Marriage_Pregnancy_and_School_Dropout.pdf. Accessed 20 Dec 2020

54. World Bank. Vietnam Country Gender Assessment. 2011. Available at: https://openknowledge.worldbank.org/handle/10986/26745. Accessed 15 Nov 2020.

55. Fegert JM, Vitiello B, Plener PL, Clemens V. Challenges and burden of the coronavirus 2019 (COVID-19) pandemic for child and adolescent mental health: a narrative review to highlight clinical and research needs in the 
acute phase and the long return to normality. Child Adolesc Psychiatry Ment Health. 2020;14(1):20. https://doi.org/10.1186/s13034-020-00329-3.

56. Orben A, Tomova L, Blakemore S. The effects of social deprivation on adolescent development and mental health. Lancet Child Adolescent Health. 2020;4(8):634-40. https://doi.org/10.1016/S2352-4642(20)30186-3.

57. Satija A, Khandpur N, Satija S, Mathur Gaiha S, Prabhakaran D, Reddy KS, et al. Physical activity among adolescents in India: a qualitative study of barriers and enablers. Health Educ Behav. 2018;45(6):926-34. https://doi. org/10.1177/1090198118778332.

58. Khan A, Burton NW, Trost SG. Patterns and correlates of physical activity in adolescents in Dhaka city, Bangladesh. Public Health (London). 2016;145:7582. https://doi.org/10.1016/j.puhe.2016.12.011.

59. Trost SG, Pate RR, Dowda M, Saunders R, Ward DS, Felton G. Gender differences in physical activity and determinants of physical activity in rural fifth grade children. J Sch Health. 1996;66(4):145-50. https://doi.org/10.1111/ j.1746-1561.1996.tb08235.x.

60. UNESCO. Adverse consequences of school closures. UNESCO. Available at: https://en.unesco.org/covid19/educationresponse/consequences. Accessed 20 Dec 2020.

61. Chatterjee $K$, Chauhan VS. Epidemics, quarantine and mental health. Med J Armed Forces India. 2020;76(2):125-7. https:/doi.org/10.1016/..mjafi.2020.03.017.

62. Elizarrarás-Rivas J, Vargas-Mendoza JE, Mayoral-García M, Matadamas-Zarate C, Elizarrarás-Cruz A, Taylor M, et al. Psychological response of family members of patients hospitalised for influenza a/H1N1 in Oaxaca, Mexico. BMC Psychiatry. 2010;10(1):104. https://doi.org/10.1186/1471-244X-10-104.

63. Yeasmin S, Banik R, Hossain S, Hossain MN, Mahumud R, Salma N, et al. Impact of COVID-19 pandemic on the mental health of children in Bangladesh: a cross-sectional study. Child Youth Serv Rev. 2020;117:105277. https://doi.org/10.1016/j.childyouth.2020.105277.

64. Sharma V, Reina OM, Sharma N. Risk and protective factors for adolescent and young adult mental health within the context of COVID-19: a perspective from Nepal. J Adolesc Health. 2020;67(1):135-7. https://doi.org/1 0.1016/j.jadohealth.2020.04.006

65. Qi M, Zhou S, Guo Z, Zhang L, Min H, Li X, et al. The effect of social support on mental health in Chinese adolescents during the outbreak of COVID-19. J Adolesc Health. 2020;67(4):514-8. https://doi.org/10.1016/.jadohealth.2020. 07.001.

66. Horesh D, Kapel Lev-Ari R, Hasson-Ohayon I. Risk factors for psychological distress during the COVID-19 pandemic in Israel: loneliness, age, gender, and health status play an important role. Br J Health Psychol. 2020;25(4): 925-33. https://doi.org/10.1111/bjhp.12455.

67. Fitzpatrick KM, Harris C, Drawve G. Fear of COVID-19 and the mental health consequences in America. Psychol Trauma. 2020;12(S1):S17-21. https://doi. org/10.1037/tra0000924.

68. Magson NR, Freeman JYA, Rapee RM, Richardson CE, Oar EL, Fardouly J. Risk and protective factors for prospective changes in adolescent mental health during the COVID-19 pandemic. J Youth Adolesc. 2021;50(1):44-57. https:// doi.org/10.1007/s10964-020-01332-9.

69. Chaplin TM, Hong K, Bergquist K, Sinha R. Gender differences in response to emotional stress: an assessment across subjective, behavioral, and physiological domains and relations to alcohol craving. Alcohol Clin Exp Res. 2008;32(7):1242-50. https://doi.org/10.1111/j.1530-0277.2008.00679.x.

70. Ramaswamy S, Seshadri S. Children on the brink: risks for child protection, sexual abuse, and related mental health problems in the COVID-19 pandemic. Indian J Psychiatry. 2020;62(9):404-13. https://doi.org/10.4103/ psychiatry.IndianJPsychiatry_1032_20.

71. Daniels M, Sharma M, Batra K. Social media, stress and sleep deprivation: a triple "S" among adolescents. J Health Soc Sciences. 2021:159-66.

72. Rowntree O. Connected Women: The Mobile Gender Gap Report 2019. GSMA Association 2019. Available at: https://www.gsma.com/ mobilefordevelopment/wp-content/uploads/2019/03/GSMA-ConnectedWomen-The-Mobile-Gender-Gap-Report-2019.pdf. Accessed 01 Mar 2021.

73. The Economist Intelligence Unit. EIU Inclusive Internet Index. Available at: https:// theinclusiveinternet.eiu.com/explore/countries/PH/. Accessed 01 Mar 2021.

74. Sarwar AH, Hossain I, Kaye T. Five Lessons Learnt from Bangladesh's Experience Responding to COVID-19. 2020. Available at: https://edtechhub. org/2020/07/15/five-lessons-learnt-from-bangladeshs-experienceresponding-to-covid-19s/. Accessed 20 Dec 2020

75. World Vision. Impact of COVID-19 to Children and Their Families: A Rapid Assessment in the Philippines. World Vision 2020. Available at: https:// reliefweb.int/report/philippines/impact-covid-19-children-and-their-familiesrapid-assessment-philippines. Accessed 15 Nov 2020

76. Bangladesh Rural Advancement Committee. Coronavirus: Let's spread awareness, not fear. Available at: https://www.brac.net/covid19/\#strategy. Accessed Feb 272021.

77. Prime $H$, Wade $M$, Browne DT. Risk and resilience in family well-being during the COVID-19 pandemic. Am Psychol. 2020;75(5):631-43. https://doi. org/10.1037/amp0000660.

78. Gariépy G, Honkaniemi H, Quesnel-Vallée A. Social support and protection from depression: systematic review of current findings in Western countries. Br J Psychiatry. 2016;209(4):284-93. https://doi.org/10.1192/bjp.bp.115.1 69094.

79. Chandrasekaran R, Mehta V, Valkunde T, Moustakas E. Topics, trends, and sentiments of tweets about the COVID-19 pandemic: temporal Infoveillance study. J Med Internet Res. 2020;22(10):e22624. https://doi.org/10.2196/22624.

80. Chaulagain A, Kunwar A, Watts S, Guerrero APS, Skokauskas N. Child and adolescent mental health problems in Nepal: a scoping review. Int J Ment Heal Syst. 2019;13(1):53. https://doi.org/10.1186/s13033-019-0310-y.

81. Ko C, Yen C, Yen J, Yang M. Psychosocial impact among the public of the severe acute respiratory syndrome epidemic in Taiwan. Psychiatry Clin Neurosci. 2006;60(4): 397-403. https//doi.org/10.1111/j.1440-1819.2006.01522x.

82. Zhou Y, Sun Z, Wang Y, Xing C, Sun L, Shang Z, et al. The prevalence of PTSS under the influence of public health emergencies in last two decades: a systematic review and meta-analysis. Clin Psychol Rev. 2021;83:101938. https://doi.org/10.1016/j.cpr.2020.101938.

83. Liu N, Zhang F, Wei C, Jia Y, Shang Z, Sun L, et al. Prevalence and predictors of PTSS during COVID-19 outbreak in China hardest-hit areas: gender differences matter. Psychiatry Res. 2020;287:112921. https://doi.org/10.1016/j. psychres.2020.112921.

84. Liang L, Ren H, Cao R, Hu Y, Qin Z, Li C, et al. The effect of COVID-19 on youth mental health. Psychiatry Q. 2020;91(3):841-52. https://doi.org/10.1 007/s11126-020-09744-3.

85. Lally J, Tully J, Samaniego R. Mental health services in the Philippines. BJPsych Int. 2019;16(3):62-4. https://doi.org/10.1192/bji.2018.34.

86. Hossain MM, Purohit N. Improving child and adolescent mental health in India: status, services, policies, and way forward. Indian J Psychiatry. 2019; 61(4):415-9. https://doi.org/10.4103/psychiatry.IndianJPsychiatry_217_18.

\section{Publisher's Note}

Springer Nature remains neutral with regard to jurisdictional claims in published maps and institutional affiliations.

Ready to submit your research? Choose BMC and benefit from:

- fast, convenient online submission

- thorough peer review by experienced researchers in your field

- rapid publication on acceptance

- support for research data, including large and complex data types

- gold Open Access which fosters wider collaboration and increased citations

- maximum visibility for your research: over $100 \mathrm{M}$ website views per year

At $\mathrm{BMC}$, research is always in progress.

Learn more biomedcentral.com/submission 